\title{
The influence of fault geometry on small strike-slip fault mechanics
}

\author{
Elizabeth Ritz ${ }^{\mathrm{a}^{* 1}}$, David D. Pollard ${ }^{\mathrm{a}}$, and Michael Ferris ${ }^{\mathrm{b}}$ \\ ${ }^{a}$ Department of Geological and Environmental Sciences, Stanford University, 450 Serra Mall, \\ Building 320, Stanford, California, 94305, USA: rritz@ alumni.stanford.edu, \\ dpollard@stanford.edu \\ ${ }^{\mathrm{b}}$ Wisconsin Institutes for Discovery at the University of Wisconsin - Madison, 330 North \\ Orchard Street, Madison, Wisconsin, 53715, USA: ferris@cs.wisc.edu \\ *Corresponding author: Elizabeth Ritz, +1.608.444.3939, lritz@ alumni.stanford.edu \\ Current work address of Elizabeth Ritz: Hess Corporation, 1501 McKinney Street, Houston, \\ Texas, 77010, USA
}

\section{Keywords}

fault shape, opening, fault mechanics, hydrothermal alteration, frictional properties

\section{Abstract}

Meter-scale subvertical strike-slip fault traces in the central Californian Sierra Nevada exhibit geometric complexities that significantly contribute to their mechanical behavior. Sections of faults that opened at depth channelized fluid flow, as evidenced by hydrothermal mineral infillings and alteration haloes. Thin sections show a variation in the style of ductile deformation of infill along the fault, with greater intensities of deformation along restraining bends. Orthorectified photo-mosaics of outcrops provide model geometries and parameter constraints used in a two-dimensional displacement discontinuity model incorporating a complementarity algorithm. Model results show that fault shape influences the distribution of opening, and consequently the spatial distribution of fluid conduits. Geometric irregularities are present at many scales, and sections of opening occur along both releasing and restraining bends. Model sensitivity tests focus on boundary conditions along the fault: frictional properties on closed sections and fluid pressure within sections of opening. The influence of the remote stress state varies along a non-planar fault, complicating the relationships between remote stresses, frictional properties, slip, and opening. Discontinuous sections of opening along model faults are similar in spatial distribution and aperture to the epidote infill assemblages observed in the field.

\section{Introduction}

Faults have irregularly shaped surfaces, and often are composed of discontinuous segments. Such irregularities cause the mechanical behavior of faults to deviate from that of the idealized planar structure. Understanding opening and slip on faults at depth is crucial to many economic and scientific applications. For example, economic geologists have noted ore deposits along geometrically complex faults for nearly a century (Cox et al., 2001; Hulin, 1929; Micklethwaite et al., 2010; Newhouse, 1940; Sibson, 1994). Fault shape also influences dynamic 
25 rupture processes, affecting both earthquake and aftershock behavior (Harris et al., 1991;

26 Micklethwaite and Cox, 2004; Ryan and Oglesby, 2014; Sibson, 1985).

This study is motivated by new field observations of meter-scale left-lateral faults in the

28 central Sierra Nevada, California (Figure 1). The faults considered in this study are within the

29 Lake Edison Granodiorite (Kle), a fine- to medium-grained biotite hornblende granodiorite

30 (Lockwood and Lydon, 1975) and one of several Late Cretaceous granitoid plutons in the area

31 (Segall et al., 1990; Stern et al., 1981). Glaciation has exposed fractures meters to kilometers in

32 length, exhumed from depths between 4 and 15 kilometers (Ague and Brimhall, 1988). Fracture

33 is used here as a general term, and includes both opening-mode and shearing-mode structures.

34 Earlier work in this area suggests that the faults developed from a single set of subvertical,

35 subparallel joints that likely formed during cooling of the pluton (Bergbauer and Martel, 1999;

36 Segall and Pollard, 1983a; Segall and Pollard, 1983b). The greater Bear Creek valley has been

37 studied as a natural laboratory for investigations of fault mechanics for several decades (for

38 example, Bürgmann and Pollard, 1992; Bürgmann and Pollard, 1994; Davies and Pollard, 1986;

39 Griffith et al., 2008; Lockwood and Lydon, 1975; Martel et al., 1988; Pachell and Evans, 2002;

40 Pennacchioni and Zucchi, 2013; Segall et al., 1990).

41 This study expands on previous work to elucidate the effect of non-planar fault shape on

42 opening and deformation of fault infill. It is suggested here that fault shape controls opening, and

43 therefore controls the spatial distribution of fluid flow along these faults, as evidenced by

44 mineralized sections of opening and local alteration of the host rock (Bürgmann and Pollard,

45 1992; Christiansen and Pollard, 1997; Griffith et al., 2009; Griffith et al., 2010; Martel et al.,

46 1988; Segall and Pollard, 1983b; Segall and Simpson, 1986; this study). Furthermore, fault shape

47 may contribute to the localization of ductile deformation within fault infill. The mechanical 
modeling presented in this study is constrained by field observations and the mechanical

49 behavior of a representative fault from the study area is evaluated. The effect of several factors

50 on slip and opening distributions along these faults are highlighted, including fault shape, two

51 frictional properties, and fluid pressure within the sections of opening.

\section{Methods}

Field observations were collected from glacially polished outcrops of the Lake Edison

54 Granodiorite using photomosaics and cylindrical core samples. Photomosaics were constructed

55 by digitally orthorectifying each photograph along the outcrop, using a square metal frame

56 included in each photograph as a guide and scale, then appropriately arranging and merging the

57 overlapping photographs. Structures and textures were then mapped from these photomosaics,

58 adding to the measurements and observations noted in the field. Core samples were drilled

59 adjacent to and along several faults using a one inch diameter bit, and thin sections were made

60 from those samples. Field work focused on an area in the Bear Creek valley along the Hilgard

61 trail, which branches east from the Pacific Crest and John Muir Trail (Figure 1).

62 The numerical results are calculated by a two dimensional displacement discontinuity

63 boundary element model (DDM) in conjunction with a complementarity solver. These quasi-

64 static experiments provide the horizontal deformation along vertical strike-slip faults and within

65 the surrounding elastic host rock. Fault slip is driven by a remote stress loading. The Ritz et al.

66 (2012) model is further developed to include fluid pressure along sections of opening, because

67 evidence for fluid flow is observed in outcrop. Ductile deformation of the fault infill is not

68 included in this elastic model, but can be indirectly modeled by adjusting contact boundary

69 conditions along the fault; ductile deformation of the host rock cannot be taken into account. The 
70 full model description is outlined in Appendix A. Matlab ${ }^{\circledR}$ code is provided in the

71 supplementary material. Right-lateral shear stresses and tensile stresses are positive.

\section{$\begin{array}{lll}72 & 3 & \text { Field observations }\end{array}$}

\section{$73 \quad 3.1 \quad$ Overview of study area and previous work}

Studies of the geochronology, field relations, and hydrothermal mineral assemblages

75 indicate that faults in the Lake Edison Granodiorite developed from subvertical cooling joints,

76 which formed soon after emplacement (Bergbauer and Martel, 1999; Segall et al., 1990). The

77 sheared joints are primarily left-lateral strike-slip faults, as evidenced by the offsetting of aplite

78 dikes and mafic xenoliths, as well as exposed slickenlines which typically plunge less than $20^{\circ}$

79 (Griffith et al., 2008; Martel et al., 1988; Segall and Pollard, 1983b). No evidence has been found

80 to suggest that slip caused in-plane propagation of the shear fractures into intact rock. Instead,

81 some small faults linked by oblique secondary opening fractures, called splay or wing cracks

82 (Segall and Pollard, 1983b). Linked faults have been observed to form larger fault zones, up to

83 thousands of meters long (Martel et al., 1988). Suggested mechanisms for fault development are

84 reviewed by Pennacchioni and Zucchi (2013) and include a regional stress rotation, large-scale

85 monoclinal kinking, or intrusion of younger plutons.

86 The joints were mineralized primarily with quartz and have preserved apertures generally

87 less than $1 \mathrm{~cm}$ (Bergbauer and Martel, 1999; Martel et al., 1988). Later slip deformed the quartz

88 infill and was accompanied by more opening along secondary fractures and between left-

89 stepping discontinuous sections of the faults. Quartz mineralization continued, as evidenced by

90 quartz-filled secondary structures, but later infill assemblages include mostly epidote with minor

91 chlorite. Relative age of the two infill assemblages is observed from crosscutting relationships. 
92 Multiple infill assemblages suggests multiple slip events, but the exact number of slip events 93 along a particular fault is difficult to infer.

94 Both ductile and brittle deformation are observed along the meter-scale faults in the Bear

95 Creek valley. Field and microstructural observations suggest that the epidote infill and localized 96 hydrothermal alteration of the host rock represent a later, lower temperature stage of reactivation

97 of small faults along which slip had been accommodated by ductile deformation (Griffith et al.,

98 2008; Pennacchioni and Zucchi, 2013). The host rock adjacent to the fault tips may have

99 experienced concurrent ductile and brittle deformation, with localized foliation development in

100 contractional steps and contractional quadrants of the fault tips, and wing crack formation in

101 dilational quadrants (Nevitt et al., 2014; Pennacchioni and Zucchi, 2013). Pennacchioni and

102 Zucchi (2013) suggest that jointing and ductile shearing alternated, or developed coevally, in

103 some locations in the Bear Creek valley. For example, ductile deformation along faults in the

104 Lake Edison Granodiorite is more pronounced along the contact with the younger Mono

105 Recesses Quartz Monzonite to the east (Bürgmann and Pollard, 1994; Pennacchioni and Zucchi,

106 2013). Because the faults in the Lake Edison Granodiorite may have spatially varying histories,

107 this study focuses on faults in a small area along the Hilgard Branch trail (Figure 1).

108 Preserved pseudotachylyte veins along some of the small faults in the Lake Edison

109 Granodiorite and nearby plutons indicate that they were seismically active (Griffith et al., 2008;

110 Kirkpatrick et al., 2009). Pseudotachylyte is discontinuous and often overprints both the quartz

111 and epidote-rich mineral infill (Griffith et al., 2008). Griffith et al. (2008) also found several

112 occurrences of thin $(\sim 200 \mu \mathrm{m})$ undeformed zeolite veins which crosscut all other fault infill

113 textures. Zeolites generally form under low-pressure conditions (Utada, 2001), and the thin

114 zeolite veins likely formed and filled at lesser depths and temperatures, after the faults became 
115 inactive. Kirkpatrick and Shipton (2009) suggest that exhumation of these faults occurred

116 without significant reactivation of the faults, thus preserving evidence of deformation at depth.

117 Late stage jointing, vertical and approximately perpendicular to older joints and faults, and

118 subhorizontal sheeting joints are the most recent structural features to form in this area.

\section{$119 \quad 3.2 \quad$ New observations of fault shape and opening at depth}

120 The faults in the study area are geometrically complex: they have curved traces, vary in

121 thickness, and often are discontinuous. Figure 2 shows three meter-scale left-lateral faults

122 mapped from photomosaics; A and B are new contributions, while LHF is a more detailed map

123 of the Lower Hilgard Meadows Fault from Griffith et al. (2009). Possible causes of fault non-

124 planarity may include non-planar joint formation (Pachell et al., 2003; Segall and Pollard,

125 1983b), linking of initially distinct joints by wing crack formation during shearing (Martel et al.,

126 1988), and ductile deformation of the granodiorite surrounding the fault surfaces (Nevitt et al.,

127 2014). The terms releasing bend and restraining bend are commonly used to describe fault

128 geometry; Figure 3a illustrates the terminology. For right-lateral slip these designations are

129 reversed.

130 The occurrence of opening at depth along the joints and faults is evidenced by

131 mineralization and alteration, both due to hydrothermal fluid circulation. Mineralized sections of

132 opening along small faults in the study area occur in two styles: lenticular opening due to 133 separation of two adjacent fault surfaces (schematic in Figure 3a and field example in Figure 4),

134 and rhombus-shaped openings connecting two fault segments at left steps (schematic in Figure $1353 \mathrm{~b}$ and field examples in Figure 5). Fault zone width that cannot be attributed to these two styles 136 of opening is assumed to be due to mineralization of the initial joint openings. 
Figure 4 shows two sets of field photos, maps, and aperture distributions along faults

138 from the study area with mineralized sections of opening and accompanying alteration haloes;

139 larger apertures are measured along releasing bends. Outcrop-scale observations indicate that the

140 infill of these two faults is predominantly epidote, with little to no quartz infill. Apertures in

141 Figure 4 are measured on the outcrop surface, approximately perpendicular to the general fault

142 trace, and are therefore apparent apertures. Releasing bends along the faults generally have 143 greater opening apertures, which can be categorized as lenticular sections of opening.

144 Rhombochasms form after linkage between two initially distinct faults or slip surfaces by an 145 extensional fracture (schematic in Figure 3b) (Griffith et al., 2009; Segall and Pollard, 1983b).

146 Figure 5b shows a rhombochasm formed by linking of two initially separate faults, and Figure 5c

147 shows a rhombochasm formed by linking of two slip patches along a single fault with earlier 148 infill. Larger steps may produce dilatant zones with multiple rhombochasms and non-linking 149 cracks. The dilational areas between faults in Figure 6 display closed, triangular, and rhombus 150 shaped splay fractures, all surrounded by altered granodiorite. The rhombochasms in Figures 5 151 and 6, which were initially open cavities, have been mineralized.

152 In the study area, mineralized sections of opening are often surrounded by 153 hydrothermally altered host rock (Figures 4, 5, and 6). The altered granodiorite appears lighter in 154 color than the unaltered granodiorite, and these areas are commonly referred to as bleached or 155 alteration haloes. Mineral infill and alteration haloes are also found around secondary fractures 156 that have formed both along the faults and at fault tips (Figure 6). Hydrothermal alteration is not 157 a regional feature, but a localized phenomenon, and is most pronounced along sections of 158 fracture opening that display the epidote-rich infill. In general, the extent of hydrothermal 159 alteration depends on host rock properties such as composition and permeability, and fluid 
160 properties such as chemistry, temperature, and pressure. Within the alteration haloes, hornblende

161 is commonly replaced by chlorite, epidote, and sphene. Biotite is replaced by chlorite, and the

162 feldspars are altered to sericite. Figure 5 shows plane light petromicrographs taken from an array

163 of samples through an alteration halo, away from the fault surface (1 through 3$)$. Sericite,

164 chlorite, and epidote all increase in abundance in the altered granodiorite, and the samples

165 become less altered with distance from the fault. The feldspar to sericite alteration makes the 166 altered granodiorite cloudy; photomicrograph 4 in Figure 5 shows the difference between highly

167 altered host rock, below the fault, and nearly unaltered granodiorite, above the fault. Biotite from

168 more distant samples are dark brown, but often alters to green chlorite closer to the fault.

169 Consistent with earlier studies, evidence suggesting that quartz is the earlier infill

170 assemblage along fractures in the study area includes rhombochasms of epidote within quartz

171 (Figure 5), discontinuous distributions of epidote infill and localized alteration, and epidote

172 fingering into cracks and void spaces within the quartz infill and host rock. Furthermore,

173 assuming that the boundary between infill and granodiorite was weaker than the solid infill of

174 either assemblage, it follows that new sections of opening exploited these preexisting surfaces of 175 weakness.

176 Figure 7 shows the apparent total aperture distribution for the completely exposed eastern

177 fault mapped in B of Figure 2, and measured from the photomosaic. Quartz is the dominant infill 178 assemblage along this fault, although discontinuous epidote rims on fault surfaces are observed

179 (Figure 8). Photomicrographs from two prominent releasing bends of this fault, provided in

180 Figure 8, show that epidote infill has a small but insignificant contribution to the total apparent

181 aperture. The quartz infill is greater than one centimeter wide along some areas the fault, within 182 releasing bends. No rhombochasms are observed along this fault. No conclusive evidence was 
183 found to suggest that this fault either initiated as one continuous joint, or as several segments

184 linked by wing cracks with ambiguously small take-off angles.

\section{Parameter constraints for numerical modeling}

Field observations from the completely exposed eastern fault mapped in B of Figure 2

187 constrain fault shape and stress boundary conditions for the model. The model fault tips are

188 along the $x$-axis (geographical azimuth approximately $070^{\circ}$ ). The orientation of the remote

189 maximum compressive stress is estimated from the wing cracks at the eastern tip of the fault.

190 Although wing cracks may have a range of take-off angles (de Joussineau et al., 2007; Martel

191 and Boger, 1998; Mutlu and Pollard, 2008), these secondary fractures turn to propagate toward

192 the direction of the remote maximum compressive stress; the tips of the wing cracks of this fault

193 are oriented $35^{\circ}$ counterclockwise from the mean azimuth of the fault trace. Wing cracks in the

194 Bear Creek valley generally strike between $15-35^{\circ}$ counterclockwise from the fault trace

195 (Bürgmann and Pollard, 1994; Segall and Pollard, 1983b). Griffith et al. (2009) concluded from

196 stress drop calculations on faults in this area that the faults are "strong" and estimated the remote

197 shear stress $\sigma_{x y}^{\infty} \simeq-200 \mathrm{MPa}$.

198 A discretized eastern fault from profile B of Figure 2 serves as the initial crack shape for

199 the following numerical experiments. Although the natural fault currently exhibits sections of 200 opening, the DDM simulates initially closed cracks. Therefore, the initial model fault surface is 201 estimated to be equidistant between the two natural fault surfaces. The straight tip-to-tip length

202 of the fault is $l=3.05 \mathrm{~m}$, but the 1,200 boundary elements used to model the fault have a total 203 length approximately $1 \mathrm{~cm}$ greater, due to non-planarity. The boundary elements vary in length 204 to more accurately account for the natural fault geometry, but have an average length of $2.55 \mathrm{~mm}$ 205 with a standard deviation of $0.54 \mathrm{~mm}$. 
The depth of the horizontal two-dimensional observation grid for the mechanical model is

207 approximately $10 \mathrm{~km}$, based on observations of Ague and Brimhall (1988). A least compressive

208 principal stress of $\sigma_{1}^{\infty}=-100 \mathrm{MPa}$ is postulated. To be consistent with the stress drop findings,

209 the most compressive principal stress is $\sigma_{3}^{\infty}=-525 \mathrm{MPa}$. Such a large remote principal stress

210 difference may have resulted from the intrusion of the Mono Creek pluton several hundred

211 meters to the northeast. Postulating that the fluid pressure was no greater than the least

212 compressive remote principal stress, the range between $0 \leq P \leq 100 \mathrm{MPa}$ is investigated.

213 Fracture permeability is taken as several orders of magnitude greater than that of a granitoid rock

214 (Kranzz et al., 1979; Pratt et al., 1977), so fluid from the fracture network would fill the newly

215 created sections of opening much more quickly than fluid from within the host rock; therefore,

216 only fluid within the fault openings is considered. All numerical experiments utilize the elastic

217 moduli of Westerly granite, with a Young's modulus of $E=70 \mathrm{MPa}$ and a Poisson's ratio of $218 v=0.25$ (Gercek, 2007).

219 Along every closed boundary element, the shear and normal stresses are related to the 220 frictional properties following:

$221 \quad\left|\sigma_{n s}\right| \leq-\mu \sigma_{n n}+S_{f}$

222 where $\mu$ is the unitless coefficient of friction and $S_{f}$ is the frictional strength with units of stress

223 (Pollard and Fletcher, 2005). Again, positive normal stress is tensile. For slip on pre-existing 224 structures, the frictional strength may be only a few megapascals (Hoskins et al., 1968), while 225 the internal frictional strength of unfractured rock is approximately $50 \mathrm{MPa}$ (Byerlee, 1978). 226 Although these faults formed from preexisting joints, mineralization of the joints may have 227 increased the frictional strength, so the range $0 \leq S_{f} \leq 50 \mathrm{MPa}$ is investigated. The range of 
228 uniform coefficients of friction applied here is $0 \leq \mu \leq 1$, because the coefficient of friction for

229 this fault is unknown.

230 The total slip observed along fault B is due to a combination of both ductile and elastic

231 processes, and multiple slip events. Evidence of both elastic and inelastic deformation along this

232 structure includes intense foliation localized between the two faults in B, and large slip gradients

233 toward the tips (Figure 2). The modeling approach employed in this study does not capture the

234 effect of inelastic deformation of the host rock, multiple slipping events, or joint infill. Instead,

235 the mechanical model is used to investigate the latest brittle slip event, when the fault geometry

236 most closely resembles what is observed in outcrop today. Therefore some numerical results,

237 including the magnitudes of slip, are not directly compared to the field example. The

238 distributions of slip and opening, and the change in their magnitudes, are the focus of the

239 following discussion.

$2405 \quad$ Numerical results

$241 \quad 5.1 \quad$ The influence of fault shape

242 In this section the mechanical behavior of faults with no frictional properties and no fluid

243 pressure, $\mu=S_{f}=P=0$, are investigated so that the effect of fault shape can be determined

244 independently. The geometric complexity of the model fault is varied to see the effects on slip

245 and opening. This is accomplished by scaling the $y$-coordinates, while fixing the corresponding

$246 x$-coordinates to produce more or less roughness. The normalized slip and opening distributions

247 for a planar fault and non-planar faults with half the measured roughness in the $y$-direction, the

248 measured roughness, and twice the measured roughness are shown in Figure 9; values

249 normalized by the maximum resultant slip for the planar fault, $D_{s}^{*}$. These distributions illustrate

250 two key observations previously mentioned in studies of slip along non-planar faults (for 
252 Pollard, 2012): non-planar faults have lesser magnitudes of mean slip than idealized planar

253 faults, and do not have the symmetrical, elliptical, distributions that are predicted for planar

254 faults with uniform stress drop (Pollard and Segall, 1987).

256 parameters held equal, is calculated as:

257 slip change $=\left[\left(\overline{D_{s}} / L\right)_{\text {non-planar }}-\left(\overline{D_{s}} / L\right)_{\text {planar }}\right] /\left(\overline{D_{s}} / L\right)_{\text {non-planar }} \times 100$

258 where the overbar indicates the mean slip. The definition in equation (2) is similar to the slip 259 deficit defined by Griffith et al. (2010), but takes into account the total length of the fault, $L$, 260 calculated by summing all element lengths. Positive slip change values indicate that the mean 261 slip on the non-planar fault is greater than the planar fault, while the opposite is true for negative 262 values. The slip change increases slightly with fault shape complexity. For the smoothed, 263 measured, and exaggerated non-planar fault shapes shown in Figure 9, the slip changes are $264-0.34 \%,-0.98 \%$, and $-2.46 \%$, respectively. The decrease in slip change is caused by 265 decreased local slip along sections of the fault that open. The slip is most perturbed along the 266 releasing bends of the non-planar fault traces; Figure 9a shows that slip locally decreases in these 267 areas. For frictionless faults, opening is a significant component of the slip surface deformation 268 along releasing bends, and opening locally limits the amount of slip.

269 Figure 9b shows that slip on non-planar faults induce several sections of opening, 270 generally with larger apertures of opening along the longest releasing bends, consistent with the 271 measured apertures presented in Figures 4 and 7. As expected, the planar fault does not open. 272 More complex fault shapes induce greater magnitudes of opening. The greatest opening 273 apertures are an order of magnitude less than the maximum slip of the non-planar faults. Figure 
$2749 \mathrm{c}$ highlights the opening results from the model geometries along one releasing bend; both the

275 aperture and length of sections of opening increase with geometric complexity. More

276 geometrically complex faults have fewer, but longer areas of opening along the fault.

$277 \quad 5.2 \quad$ Sensitivity tests with frictional properties and fluid pressure

Here the influence of three poorly constrained parameters on the mechanical behavior of

279 the non-planar model fault are discussed: the coefficient of friction, frictional strength, and fluid

280 pressure. In this section, fault openings are traction-free unless a non-zero fluid pressure is

281 designated. Fluid pressure is $\sigma_{n n}^{\text {open }}=-P$ along open elements, and the coefficient of friction and

282 frictional strength are eliminated to reflect a shear-traction-free boundary condition. The broad

283 influence of the coefficients of friction $0 \leq \mu \leq 1$, frictional strengths $0 \leq S_{f} \leq 50 \mathrm{MPa}$, and fluid

284 pressures $0 \leq P \leq 100 \mathrm{MPa}$ on the mechanical behavior of the discretized non-planar fault $\mathrm{B}$ are

285 investigated in this section. While the influence of any one parameter is tested, the other two are 286 set to zero.

287 Figure 10 presents normalized slip and opening distributions for faults with varying 288 coefficients of friction, frictional strengths, and fluid pressures in sections of opening. Each 289 profile is normalized by the greatest magnitude for the planar simulation with $\mu=S_{f}=P=0$.

290 The slip distributions and magnitudes are most sensitive to changes within the range of tested 291 coefficient of friction, with greater departures from an elliptical slip distribution (Figure 11a).

292 For the non-planar fault with $\mu=1$, no slip occurs along the model fault, resulting in a $-100 \%$ 293 slip change relative to the planar fault under the same conditions.

294 Figure 10b, d, and f presents the opening distributions for model faults with a range of 295 frictional properties and fluid pressures. The occurrence and extent of opening is more sensitive 296 to changes within the range of tested coefficients of friction than frictional strength and fluid 
297 pressure. The slip change metric (2) inspires another metric to describe the change in opening 298 between two non-planar model results:

299 opening change $=\left[\left(\overline{D_{n}}\right)_{\text {test }}-\left(\overline{D_{n}}\right)_{\text {base }}\right] /\left(\overline{D_{n}}\right)_{\text {base }} \times 100$

300 where base denotes the mean normal displacement discontinuity from a numerical experiment 301 with $\mu=S_{f}=P=0$ and test denotes the result from an experiment testing one of those three

302 parameters. A base case non-planar fault is used instead of a planar fault because planar faults do 303 not open. The percentage of opening change for the coefficient of friction, frictional strength, 304 and fluid pressure is shown in Figure 11b. Unsurprisingly, the mean opening decreases along the 305 fault with an increase in either frictional property, and opening increases with an increase in fluid 306 pressure. Less intuitive results are discussed below.

\section{Discussion}

308 Figure 8 not only illustrates that the aperture and infill material vary along a single fault, 309 but also that the deformation of the fault infill varies along its strike. Along releasing bends the 310 quartz infill shows undulose extinction, subgrain formation and recrystallization, and grain 311 bulging (Figure 8a and c). Large, euhedral grains of epidote are observed along the fault 312 surfaces, but also ribbons of smaller, pulverized grains. In contrast, Figure $8 \mathrm{~b}$ shows mylonitized 313 quartz infill and host rock between the restraining bend fracture surfaces; darker ribbons are 314 smeared biotite, although most of the mylonitized material is quartz and feldspar. These 315 observations, and similar observations from within in the study area, suggest that deformation of 316 the initial joint infill material varies along geometrically complex faults. Restraining bends

317 display mylonite fabrics within the quartz infill, with more progressed grain size refinement than 318 observed in releasing bends. 
Although the joints may have had non-uniform apertures, previous numerical mechanical

320 modeling by Ritz and Pollard (2012) suggests that slip can lead to a systematic pattern of

321 discontinuous lenses of opening along releasing bends of simplified sinusoidal non-planar faults.

322 Fault widths in the Bear Creek valley are generally greater than joint widths, according to Segall

323 and Pollard (1983b), and continued opening during slip may contribute to this disparity, so that

324 releasing bends systematically exhibit greater apertures than restraining bends. Figure 8 shows

325 that, although restraining bends (8b) and releasing bends (8a and c) both may have apparent

326 apertures, fault thickness is attributed to a zone of ductile deformation along restraining bends

327 and releasing bends have greater apertures due to fault surface separation and subsequent

328 mineralization.

329 Changes in the size of sections of opening depend on position, length, and aperture

330 distribution (for example, Figure 9c). The total apparent apertures observed in outcrop along the

331 fault B are an order of magnitude greater than those of the model. Internal fluid pressure is one

332 mechanism that can cause greater apertures, although the numerical results show that adding

333 fluid pressure to open sections does not increase the apertures tenfold. The opening calculated

334 with the numerical model is similar, however, to both the distribution and width of the epidote

335 infill observed along the fault in outcrop and thin section, although the total aperture along the

336 fault is attributable to multiple slip events.

337 Geometric barriers impede slip along a non-planar fault. Griffith et al. (2010) found that

338 the effect of elevated normal stress along these geometric barriers, or restraining bends, may be

339 at least partially counteracted by opening along releasing bends, or temperature-related

340 weakening mechanisms such as the formation of pseudotachylyte during seismic slip. Mylonite

341 formation also may be a mechanism that accommodates strain preferentially on restraining 
342 bends. Figure 12 shows the variation in normal and shear stress magnitude before deformation,

343 which are the remote stresses resolved along the initial fault shape. Before deformation, normal

344 and shear stresses are elevated on restraining bends of the fault and reduced on releasing bends,

345 relative to a planar fault. The range in magnitude for the normal stress resolved along the length

346 of the non-planar fault is approximately $200 \mathrm{MPa}$, while the range in resolved shear stress is

347 approximately $50 \mathrm{MPa}$.

348 For the numerical results, varying the magnitudes of frictional strength or fluid pressure

349 have little influence on slip distributions, but varying the coefficient of friction within the tested

350 range can produce slip distributions that diverge greatly from elliptical (Figure 10a). The non-

351 linear trend in slip change for the coefficient of friction (Figure 11a) also reflects this variation in

352 slip distributions and magnitudes. Figure 10a illustrates that local maxima in the slip distribution

353 switch from restraining bends to releasing bends as the coefficient of friction increases. This is

354 likely due to the increase of the physical resistance to slip that the addition of frictional

355 properties present to the restraining bends, which already host greater normal stress due to their

356 orientation with respect to the remote stress state. With non-zero frictional properties, opening is

357 more prevalent along releasing bends (Figure 10b), reducing the resistance to slip that those

358 elements would otherwise provide. Opening along releasing bends has the opposite effect for

359 non-planar faults with lesser frictional properties, due to greater separation of the fault surfaces

360 inhibiting the slip deformation. For example, the base case non-planar fault with no frictional

361 properties or fluid pressure has locally reduced slip along the releasing bends (darkest gray line

362 in Figure 10a) but with increased coefficients of friction the slip is locally increased along

363 releasing bends. 
Within the tested ranges of fluid pressure, increased $P$ along sections of opening allow

365 the non-planar faults to have greater mean slips than the fluid-free base case non-planar fault, but

366 not the planar faults with comparable parameters. This is likely due to the increased number of

367 elements with zero shear traction, as a longer length of fault opens due to the fluid pressure

368 pushing the fault surfaces apart within those sections of opening. Figure $11 \mathrm{~b}$ shows that greater

369 mean opening apertures are produced for greater fluid pressures.

370 The impact of either frictional property on the shear stress along the fault depends on the

371 value of the normal stress. If the two terms $-\mu \sigma_{n n}$ and $S_{f}$ are equivalent, they have the same

372 influence on the shear stress, which ultimately drives slip. The larger of the two terms is

373 therefore more important to the mechanical behavior of the fault in general. Figure 13 shows the

374 parameter space for the range of frictional properties investigated, with lines indicating that the

375 two terms equally contribute to the magnitude of the shear stress. To the left of each line, the

376 frictional strength term will be greater than the product of the coefficient of friction and normal

377 stress. To the right of each line, the opposite is true, and the coefficient of friction is more

378 influential. Uniform $\mu$ and $S_{f}$ are assigned for an entire fault in this model, which can be

379 mapped as a point in Figure 13. However, Figure 12 demonstrates that the resolved normal stress

380 along the model fault is non-uniform. A range of normal stresses along the fault corresponds to a

381 vertical range in Figure 13, so both frictional properties may have an influence along different

382 sections of non-planar fault. According to Figures 12 and 13, the frictional strength is more

383 likely to have a greater influence than the coefficient of friction on releasing bends, while the

384 coefficient of friction will likely be the dominant frictional property on restraining bends.

385 Remote stress states at shallower depths or with lesser principal stress differences would result in 
lesser magnitudes of resolved normal stress along the model fault, which would expand the parameter space for which the frictional strength term is more influential.

The numerical technique used in this study can also be employed to predict off-fault 389 damage along non-planar faults; stress magnitudes constrain the spatial distribution, stress 390 orientations constrain the orientation, and the sign of the stress constrains the style of damage.

391 Griffith et al. (2010) found that microcrack density along a strand of the Gole Larghe fault zone 392 in the Adamello batholith, southern Italian Alps, varies systematically with fault shape and is 393 associated with the static stresses rather than transient stresses due to dynamic processes. Greater 394 microcrack densities were measured along releasing bends of the Italian fault than the restraining 395 bends. These observations warrant further investigation on the relationship between fault shape 396 and off-fault damage, in igneous and other rock types. Other studies have shown that fluid flow 397 and mineralization also can occur outside the main fault, often controlled by inelastic 398 deformation (Micklethwaite and Cox, 2004; Micklethwaite and Cox, 2006; Sheldon and 399 Micklethwaite, 2007). The numerical technique used in this study cannot account for inelastic 400 deformation of the host rock and does not include secondary structures, so predictions about 401 mineralization outside of the faults are not made here.

\section{Conclusions}

403 Fault traces mapped in the Sierra Nevada exhibit geometric complexities that 404 significantly contribute to their mechanical behavior. The field observations provide model 405 geometries and parameter constraints used to investigate the effect of fault shape, frictional 406 properties, and the presence of fluid pressure in sections of opening along a small left-lateral 407 fault. Opening only occurs along faults with non-planar geometries, not along planar faults with 408 non-uniform frictional properties. Fault shape therefore is the first order control on the spatial 
409 distribution of fluid along faults. Although opening is greater on releasing bends, sections of 410 opening on restraining bends demonstrate that using more objective terms to describe the fault 411 shape is appropriate. For suggested terminology see Ritz and Pollard (2012), who introduce the 412 objective terms stoss and lee. Sections of opening channelize fluid flow, as evidenced by 413 mineralized openings and alteration haloes in the field area. The discontinuous sections of 414 opening calculated with the elastic model have apertures less than a few millimeters, similar in 415 aperture and distribution to the epidote infill observed in outcrop and thin section. However, the 416 distribution of total apparent opening measured from outcrop photos and calculated from the 417 modeling are also similar (Figure 7 compared to Figures 9 and 10). Additionally, increased 418 compression along restraining bends due to fault non-planarity may cause mylonitization of the 419 earlier fault infill along those sections. Mylonites were observed along restraining bends of the 420 small left-lateral faults but not along releasing bends, despite similar infill thicknesses and slip, 421 suggesting that fault shape is an important factor in the style of infill deformation within faults in 422 the study area.

423 Geometric irregularities along non-planar faults generally lead to lesser mean slips 424 relative to idealized planar faults under the same conditions. The addition of fluid pressure 425 enlarges sections of opening, while the two frictional properties decrease mean opening. 426 Increased opening, chemical alteration, and precipitation of new minerals due to the presence of 427 fluid may change the rheological properties of the host rock and strength of the fault surfaces. 428 The coefficient of friction strongly influences both the magnitude and distribution of opening 429 and slip, whereas the frictional strength has little effect on distributions of opening and slip. The 430 spatial distribution and size of sections of opening along a non-planar fault are most sensitive to 431 fault shape, the coefficient of friction, and fluid pressure. Variation in stresses along non-planar 
432 faults highlights the importance of achieving a better understanding of how fault shape

433 influences deformation, both along and alongside of the fault surfaces, and complicates the effect

434 of frictional properties. Furthermore, geometric irregularities occur along fractures at many

435 scales and the slip and opening behavior of each irregularity will constructively or destructively

436 interfere with the next. While this study focused on meter-scale natural faults, the model results

437 may be applicable to larger structures with dominantly elastic host rock. For faults at the

438 kilometer-scale and greater, for example, gravity becomes significant and the modeling

439 technique used here may not be applicable.

440 Appendix A

441 This implementation of a two-dimensional displacement discontinuity method (DDM)

442 (Crouch 1976; Crouch and Starfield, 1983) in combination with a complementarity solver is

443 similar to that of Ritz et al. (2012), with two main departures: it includes a more efficient

444 implementation of the complementarity solver PATH (Dirkse and Ferris, 1995; Ferris and

445 Munson, 1999), and the addition of an normal stress, $\sigma_{n n}^{\text {open }}$, which only acts on open elements

446 along the fractures. The additional normal stress can be used as a proxy for fluid pressure, among

447 other physical processes, and is included through an iterative scheme. This allows for tracking

448 the effect that fluid pressure within sections of opening has on the mechanical deformation of the 449 entire structure.

450 Quasi-static numerical experiments are conducted on cracks, which act as models for 451 vertical fractures. Cracks are discretized into linear segments called boundary elements of 452 constant displacement discontinuity, while the surrounding rock is assumed to be a 453 homogeneous, isotropic, linear elastic material (Figure A1). Certain constraints or conditions can 454 be specified for any or all boundary elements, and boundary conditions define the other relevant 
parameters. The solution, the shear and normal displacement discontinuities and the shear and

456 normal stresses for each element, are found by summing the effects of each boundary element on

457 the others. The stresses are only specified at the element midpoints; therefore, the DDM solution

458 will match prescribed traction conditions only at the midpoints of the elements. Tension is

459 positive in this sign convention, which follows Crouch and Starfield (1983).

460 Changing the number of boundary elements will change the shape of the model fault.

461 Increasing the number of elements will produce a more accurate solution. As an example, every

462 other boundary element from an initial discretization of 1,200 was eliminated to smooth the

463 eastern fault from profile B (Figure 3), and Figure A2 shows that the percent change in the

464 maximum aperture, $D_{n}^{*}$, and maximum slip, $D_{s}^{*}$, for several smoothed versions of the original

465 fault shape. The percent change decreases rapidly as the discretization of the natural fault

466 becomes more precise. The percentage change of $D_{n}^{*}$ and $D_{s}^{*}$ from 600 to 1,200 boundary

467 elements are less than one percent each. Stress fields in the elastic material are calculated with

468 the displacement discontinuities, so the precision of $D_{n}$ and $D_{s}$ correlates with the precision of

469 the resulting stress field as well as the opening and slip distributions.

470 The stresses $\sigma_{n n}$ and $\sigma_{n s}$ at the midpoint of each element $i=1$ to $N$ are related to the

471 uniform displacement discontinuities $D_{n}$ and $D_{s}$ for the same element and all others, denoted by

$472 j=1$ to $N$ (Crouch and Starfield, 1983, p. 88):

473

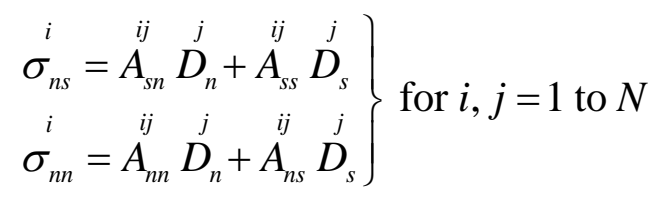

474 where $A_{n n}^{i j}, A_{n s}^{i j}, \stackrel{i j}{A_{s n}}$, and $\stackrel{i j}{A_{s s}}$ are influence coefficients from the original DDM formulation 475 (Crouch and Starfield, 1983, p. 93). 
The DDM does not include frictional contact properties because interpenetration is

477 allowed, preventing contact between the two crack surfaces. A complementarity algorithm adds a 478 mathematical optimization scheme to correct the initial DDM solution and enforce contact 479 boundary conditions along the cracks, such as stick-slip behavior. Since the behavior of each 480 boundary element is not known a priori, the complementarity solver utilizes the basic 481 relationships between sticking, slipping, and opening to correct the DDM solution. The 482 following conditions, written in terms of the element-local stress and displacement discontinuity 483 components, are true for every element:

484 1) $D_{n} \leq 0$, where the equality implies that the surfaces are in contact and the inequality implies 485 opening;

486 2) $\sigma_{n n} D_{n}=0$, because $D_{n}=0$ if the surfaces are in contact and $\sigma_{n n}=0$ if no fluid is present;

487 3) $\left|\sigma_{n s}\right| \leq-\mu \sigma_{n n}+S_{f}$, where the equality implies sliding and the inequality implies sticking 488 (Figure A2); and

489 4) $\sigma_{n s} D_{s} \leq 0$, since a positive shear stress on the crack surface drives a negative shear 490 displacement discontinuity, and vice versa (Figure A3).

491 Frictional strength $S_{f}$ is the resistance to slip without a normal stress. Condition 1 prevents 492 interpenetration. The additional $\sigma_{n n}^{\text {open }}$ along elements that open is included in a later step; 493 therefore, condition 2 is written for normal-traction-free sections of opening along the fault. 494 Conditions 3 and 4 suggest that if the element slips sinistrally, then

$495 \quad D_{s}>0$ and $\sigma_{n s}=\mu \sigma_{n n}-S_{f}$

496 and if the element slips dextrally, then

$497 \quad D_{s}<0$ and $\sigma_{n s}=-\mu \sigma_{n n}+S_{f}$ 
499 with the following six relationships:

$500 \quad \stackrel{i}{\sigma_{n s}}=\stackrel{j}{\sigma_{n s}^{\infty}}+\stackrel{i j}{A_{s n}} \stackrel{j}{D_{n}}+\stackrel{i j}{A_{s s}} \stackrel{j}{D_{s}}$

501 which is made orthogonal $(\perp)$ to the free variable $\sigma_{n s}^{i}$, along with

$502 \quad \stackrel{i}{\sigma_{n n}}=\stackrel{j}{\sigma_{n n}^{\infty}}+\stackrel{i j}{A_{s n}} \stackrel{j}{D_{n}}+\stackrel{i j}{A_{s s}} \stackrel{j}{D_{s}} \perp \stackrel{i}{D_{n}}$ free

$503 \quad \stackrel{i}{D_{s}}=\stackrel{i}{D_{s}^{R}}-\stackrel{i}{D_{s}^{L}} \perp \stackrel{i}{D_{n}}$ free

504 where $D_{s}^{R}$ and $D_{s}^{L}$ are the non-negative components of right- and left-lateral slip for each

505 element, respectively (Figure A4), and also

$506 \quad \stackrel{i}{D_{n}} \leq 0 \perp \sigma_{n n}^{i} \leq 0$

$507 \quad 0 \leq{\stackrel{i}{\sigma_{n s}}}-{\stackrel{i}{\sigma_{n n}}}_{\mu} \stackrel{i}{\mu}+\stackrel{i}{S}_{f} \perp \stackrel{i}{D_{s}^{R}} \geq 0$

$508 \quad 0 \leq-\sigma_{n s}^{i}-i_{n n}^{i} \stackrel{i}{\mu}+\stackrel{i}{S}_{f} \quad \perp \quad \stackrel{i}{D}^{L} \geq 0$

509 Expressions on the left of relationships (7)-(12) are assembled into the left-had side of the

510 complementarity equation $f(Z)=M Z+Q$, while the expressions on the right of relationships

511 (7)-(12) are assembled into the vector $Z$ :

512

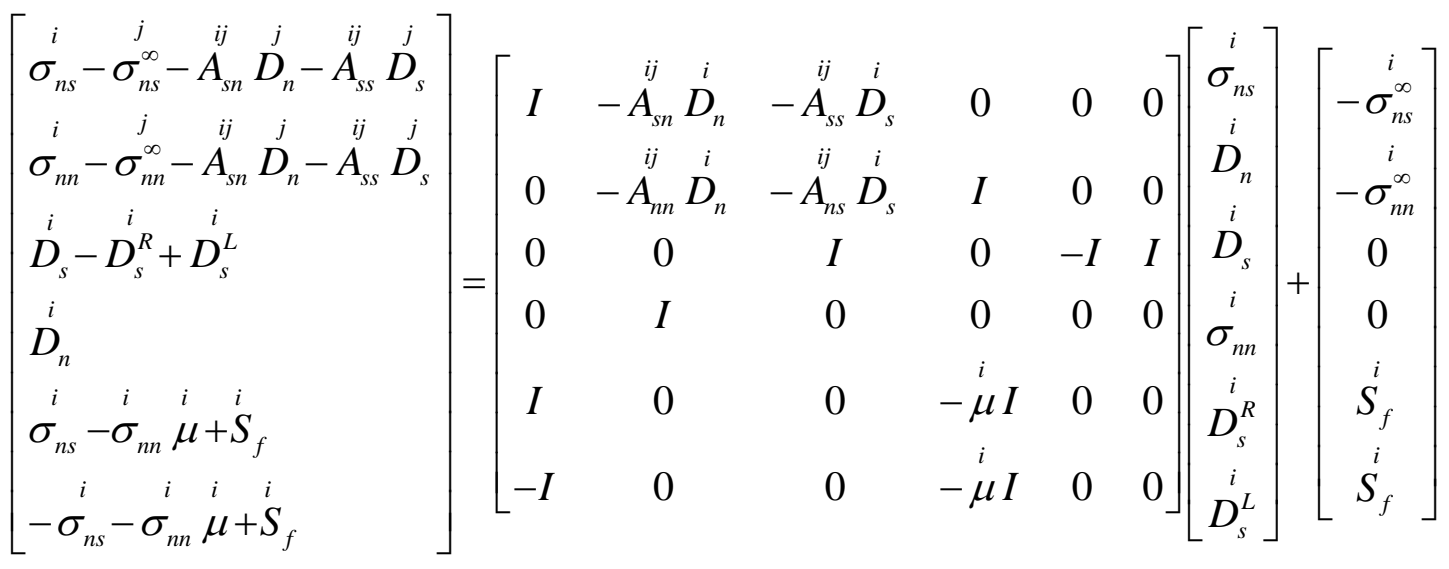


513 where $I$ is an $n \times n$ identity matrix and 0 is an array of zeros. Vectors $\sigma_{n s}^{\infty}$ and $\sigma_{n n}^{\infty}$ are lists of

514 the resolved remote stresses acting on each element, calculated in the DDM formulation.

515 Complementarity constraints require that, for each component in the $6 N \times 1$ arrays $Z$

516 and $f(Z)$, either the component in $Z$ or the corresponding component in the non-linear

517 function $f(Z)$ is an equality, and the product of the two components is zero. For example, since

518 the relationships to the left of the orthogonal disjunction symbol $\perp$ in (7)-(9) above are

519 equalities, the three variables to the right are free: $\sigma_{n s},-D_{n}$, and $D_{s}$. Free variables are

520 boundless, and can therefore range from negative to positive infinity. Bounds ( $l$ for lower and $u$

521 for upper) on variables in other subarrays of $Z_{\text {sub }}^{i}$ and $f\left(Z_{\text {sub }}^{i}\right)$ determine the meaning of $\perp$ :

522 if $\left\{\begin{array}{ccc}Z_{\text {sub }}^{i} \geq 0 & Z_{\text {sub }}^{i} \geq 0 \perp f\left(Z_{\text {sub }}^{i}\right) \geq 0 & Z_{c}^{i} \times f\left(Z_{\text {sub }}^{i}\right)=0 \\ Z_{\text {sub }}^{i} \leq u & \text { then } Z_{\text {sub }}^{i} \leq u \perp f\left(Z_{\text {sub }}^{i}\right) \leq 0 & \text { and }\left(u-Z_{\text {sub }}^{i}\right) \times f\left(Z_{\text {sub }}^{i}\right)=0 \\ l \leq Z_{\text {sub }}^{i} & l \leq Z_{\text {sub }}^{i} \perp f\left(Z_{\text {sub }}^{i}\right) \geq 0 & \left(Z_{\text {sub }}^{i}-l\right) \times f\left(Z_{\text {sub }}^{i}\right)=0\end{array}\right.$

523 The subscript in $Z_{\text {sub }}^{i}$ denotes the targeted relationship from sets (7) to (9), while the overscript

524 denotes the range of boundary elements. The lower bounds on the variables in $Z$, which are

525 consistent for all boundary elements $i=1$ to $N$ are

$526 \quad l=\left[\begin{array}{llllll}-\infty & -\infty & -\infty & -\infty & 0 & 0\end{array}\right]^{\mathrm{T}}$

527 and upper bounds on $Z$ are $u=\left[\begin{array}{llllll}\infty & \infty & \infty & 0 & \infty & \infty\end{array}\right]^{\mathrm{T}}$

528 where each component in (15) and (16) is an $i \times 1$ array. The bounds on the variables in $Z$ are

529 thus: $-\infty \leq \sigma_{n s}^{i} \leq \infty,-\infty \leq \stackrel{i}{D}_{n} \leq \infty,-\infty \leq \stackrel{i}{D_{s}} \leq \infty,-\infty \leq{ }_{\sigma_{n n}}^{i} \leq 0,0 \leq{\stackrel{i}{D_{s}^{R}}}^{R} \leq \infty, 0 \leq D_{s}^{L} \leq \infty$. Tensile

530 normal stresses along the elements are not permitted, and the variables $D_{s}^{R}$ and $D_{s}^{R}$ are positive. 
The first solution using the complementarity algorithm is found with the above

532 implementation, and open elements can be identified from this initial solution. In order to include

533 the additional internal normal stress $\sigma_{n n}^{\text {open }}$ along elements that open, one set of bounds is altered

534 before resolving the problem. Only for these open elements, both the lower and upper bounds of

$535 \sigma_{n n}$ are set to the user-determined value of $\sigma_{n n}^{o p e n}$ in order to force the normal stress on that

536 element to be $\sigma_{n n}=\sigma_{n n}^{\text {open }}$. When this variable is doubly-bounded (there is both an upper and

537 lower bound) one of the following four cases is true:

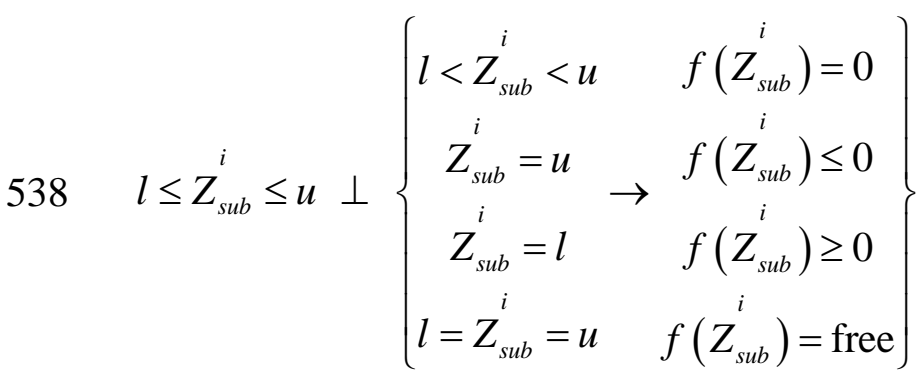

539 For this application, the bounds on $\sigma_{n n}$ are changed to $l=\sigma_{n n}=u \perp \mathrm{D}_{n}$ free, and $l=u=\sigma_{n n}^{\text {open }}$.

540 The new solution will not include $\sigma_{n n}^{\text {open }}$ along elements that open due to the mechanical effect of

$541 \sigma_{n n}^{o p e n}$ along the previously opened elements. Therefore, new bounds must be set and the solution

542 iteratively solved until no new elements open.

543 With or without including fluid pressure, the shear traction along elements that open

544 needs to be reset to $\mu=S_{f}=0$, since fluid only exerts a normal pressure and the openings are

545 shear-traction-free. This adjustment is done within the same iterative loop as the implementation

546 of the fluid pressure, and may trigger additional iterations to reach equilibrium.

Under the current bounds, with $\sigma_{n n}^{\text {open }}<0$, the additional internal normal stress along the

548 crack can be used as a proxy for several processes, including the presence of fluid, dilational

549 gouge, or magma. Similarly, if $\sigma_{n n}^{\text {open }}>0$, the additional normal tensile stress along the crack can 
550 be used as a proxy for a "fault pump" scenario (Sibson et al., 1975), or to force the fault closed.

551 A list of $N$ values of $\sigma_{n n}^{\text {open }}$ is specified as an input parameter, but any single value is only called

552 if the corresponding element opens (if $D_{n}<0$ ). Non-uniform values of $\sigma_{n n}^{\text {open }}$ are possible, but a

553 physical rationale would be needed to support the differences in magnitude and/or sign between

554 the elements.

555 This arrangement allows one to model, for example, the physical process of fluid flow

556 entering open spaces along a fracture or fault. The fluid pressure $P$ would force the open

557 elements to remain open and change the normal pressure acting on the fracture walls along the

558 sections of opening to a new value, $\sigma_{n n}^{\text {open }}=P$. Resolving the reduced mixed complementarity

559 problem may determine that new elements open due to the fluid pressure acting on previously

560 opened elements; if so, the normal stress along the newly opened elements also will be set to

$561 \quad \sigma_{n n}^{o p e n}=P$ and the shear stresses to $\sigma_{n s}=0$, and the calculations repeated until no new elements

562 open. Although no time steps are considered here, one can record the effect of the proxy

563 parameter $\sigma_{n n}^{\text {open }}$ on the evolution of a section of opening.

564 One major advantage of using a DDM is that only discretization of the crack is required,

565 whereas other popular methods require discretization of the surrounding material. Additionally,

566 several optional steps are taken to increase the computational efficiency of PATH. The solution

567 for the stresses at the center of each element are initialized as the resolved remote stresses for

568 each element in the $Z$ array for the complementarity solver. The resolved remote stresses are

569 already calculated within the DDM formulation, so no further calculations are needed. If

570 subsequent iterations are needed, the previous solution for $Z$ is the starting point. Another step

571 taken to increase efficiency is to scale the $D_{n}$ and $D_{s}$ parameters and the components $D_{s}^{R}$ and 
$572 D_{s}^{L}$ that are used in the complementarity solver and then rescale the solution for these parameters

573 and components. This is helpful because the values of the stresses and displacements differ by

574 several orders of magnitude. The smaller displacements are scaled when implementing

575 relationships (7) and (8) (see code). Another advantage of this method over the method described

576 in (Ritz et al., 2012) is that the inverse of the influence coefficients is not found before utilizing

577 the complementarity solver, since that calculation is handled within the complementarity solver.

578 Lastly, the stress slack variables utilized in (Ritz et al., 2012) are no longer needed.

\section{Acknowledgements}

04ER15588-5, Basic Energy Sciences Program and the McGee research fund of the department

583 Ashley W. Griffith for assistance in the field and continued discussions. We would also like to

584 thank our reviewers for constructive feedback.

\section{References}

585 Ague, J.J., Brimhall, G.H., 1988. Magmatic arc asymmetry and distribution of anomalous 586 plutonic belts in the batholiths of California: Effects of assimilation, crustal thickness, and depth 587 of crystallization. Geological Society of America Bulletin 100, 912-927.

588 Bergbauer, S., Martel, S.J., 1999. Formation of joints in cooling plutons. Journal of Structural 589 Geology 21, 821-835.

590 Bürgmann, R., Pollard, D.D., 1992. Influence of the state of stress on the brittle-ductile transition 591 in granitic rock - evidence from fault steps in the Sierra-Nevada, California. Geology 20, 645592648.

593 Bürgmann, R., Pollard, D.D., 1994. Strain accommodation about strike-slip-fault discontinuities 594 in granitic rock under brittle-to-ductile conditions. Journal of Structural Geology 16, 1655-1674.

595 Byerlee, J., 1978. Friction of rocks. Pure and Applied Geophysics 116, 615-626. 
Christiansen, P.P., Pollard, D.D., 1997. Nucleation, growth and structural development of mylonitic shear zones in granitic rock. Journal of Structural Geology 19, 1159-1172.

598 Cox, S., Knackstedt, M., Braun, J., 2001. Principles of structural control on permeability and 599 fluid flow in hydrothermal systems. Reviews in Economic Geology 14, 1-24.

600 Davies, R.K., Pollard, D.D., 1986. Relations between left-lateral strike-slip faults and right601 lateral monoclinal kink bands in granodiorite, Mt. Abbot quadrangle, Sierra Nevada, California. 602 Pure and Applied Geophysics 124, 177-201.

603 de Joussineau, G., Mutlu, O., Aydin, A., Pollard, D.D., 2007. Characterization of strike-slip 604 fault-splay relationships in sandstone. Journal of Structural Geology 29, 1831-1842.

Dieterich, J.H., Smith, D.E., 2009. Nonplanar Faults: Mechanics of Slip and Off-fault Damage. Pure and Applied Geophysics 166, 1799-1815.

Dirkse, S.P., Ferris, M.C., 1995. The PATH solver: A non-monotone stabilization scheme for mixed complementarity problems. Optimization Methods and Software 5, 123-156.

Ferris, M.C., Munson, T.S., 1999. Interfaces to PATH 3.0: Design, Implementation and Usage. Computational Optimization and Applications 12, 207-227.

611 Gercek, H., 2007. Poisson's ratio values for rocks. International Journal of Rock Mechanics and 612 Mining Sciences 44, 1-13.

613 Griffith, W.A., Di Toro, G., Pennacchioni, G., Pollard, D.D., 2008. Thin pseudotachylytes in 614 faults of the Mt. Abbot quadrangle, Sierra Nevada: Physical constraints for small seismic slip 615 events. Journal of Structural Geology 30, 1086-1094.

616 Griffith, W.A., Di Toro, G., Pennacchioni, G., Pollard, D.D., Nielsen, S., 2009. Static stress drop 617 associated with brittle slip events on exhumed faults. J. Geophys. Res. 114.

618 Griffith, W.A., Nielsen, S., Di Toro, G., Smith, S.A.F., 2010. Rough faults, distributed 619 weakening, and off-fault deformation. J. Geophys. Res. 115, B08409.

620 Harris, R.A., Archuleta, R.J., Day, S.M., 1991. Fault steps and the dynamic rupture process; 621 numerical simulations of a spontaneously propagating shear fracture. Geophys. Res. Lett. 18, $622893-896$. 
623 Hoskins, E.R., Jaeger, J.C., Rosengren, K.J., 1968. A medium-scale direct friction experiment. 624 International Journal of Rock Mechanics and Mining Sciences \&amp; Geomechanics Abstracts 625 5, 143-152.

626 Hulin, C.D., 1929. Structural control of ore deposition. Economic Geology 24, 15-49.

627 Kirkpatrick, J.D., Shipton, Z.K., 2009. Geologic evidence for multiple slip weakening 628 mechanisms during seismic slip in crystalline rock. J. Geophys. Res. 114, B12401.

629 Kirkpatrick, J.D., Shipton, Z.K., Persano, C., 2009. Pseudotachylytes: Rarely Generated, Rarely 630 Preserved, or Rarely Reported? Bulletin of the Seismological Society of America 99, 382-388.

631 Kranzz, R.L., Frankel, A.D., Engelder, T., Scholz, C.H., 1979. The permeability of whole and 632 jointed Barre Granite. International Journal of Rock Mechanics and Mining Sciences \& 633 Geomechanics Abstracts 16, 225-234.

634 Lockwood, J.P., Lydon, P.A., 1975. Geologic map of the Mount Abbot quadrangle, central 635 Sierra Nevada, California. United States Geological Survey, pp. Quadrangle Map GQ-1155.

636 Marshall, S.T., Morris, A.C., 2012. Mechanics, Slip Behavior, and Seismic Potential of 637 Corrugated Dip Slip Faults. Journal of Geophysical Research-Solid Earth 117, 1987-2012.

638 Martel, S.J., Boger, W.A., 1998. Geometry and mechanics of secondary fracturing around small 639 three-dimensional faults in granitic rock. Journal of Geophysical Research-Solid Earth 103, $640 \quad 21299-21314$.

641 Martel, S.J., Pollard, D.D., Segall, P., 1988. Development of simple strike-slip fault zones, 642 Mount Abbot Quadrangle, Sierra-Nevada, California. Geological Society of America Bulletin 643 100, 1451-1465.

644 Micklethwaite, S., Cox, S.F., 2004. Fault-segment rupture, aftershock-zone fluid flow, and 645 mineralization. Geology 32, 813-816.

646 Micklethwaite, S., Cox, S.F., 2006. Progressive fault triggering and fluid flow in aftershock 647 domains: Examples from mineralized Archaean fault systems. Earth and Planetary Science 648 Letters $250,318-330$. 
Micklethwaite, S., Sheldon, H.A., Baker, T., 2010. Active fault and shear processes and their 650 implications for mineral deposit formation and discovery. Journal of Structural Geology 32, 151651165.

652 Mutlu, O., Pollard, D.D., 2008. On the patterns of wing cracks along an outcrop scale flaw: A 653 numerical modeling approach using complementarity. J. Geophys. Res. 113.

654 Nevitt, J.M., Pollard, D.D., Warren, J.M., 2014. Evaluation of transtension and transpression 655 within contractional fault steps: Comparing kinematic and mechanical models to field data. 656 Journal of Structural Geology 60, 55-69.

657 Newhouse, W.H., 1940. Openings due to movement along a curved or irregular fault plane. 658 Economic Geology 35, 445-464.

659 Pachell, M.A., Evans, J.P., 2002. Growth, linkage, and termination processes of a 10-km-long 660 strike-slip fault in jointed granite: the Gemini fault zone, Sierra Nevada, California. Journal of 661 Structural Geology 24, 1903-1924.

662 Pachell, M.A., Evans, J.P., Taylor, W.L., 2003. Kilometer-scale kinking of crystalline rocks in a 663 transpressive convergent setting, Central Sierra Nevada, California. Geological Society of 664 America Bulletin 115, 817-831.

665 Pennacchioni, G., Zucchi, E., 2013. High-temperature fracturing and ductile deformation during 666 cooling of a pluton: the Lake Edison granodiorite (Sierra Nevada batholith, California). Journal 667 of Structural Geology 50, 54-81.

668 Pollard, D.D., Fletcher, R.C., 2005. Fundamentals of structural geology. Cambridge University 669 Press.

670 Pollard, D.D., Segall, P., 1987. Theoretical displacements and stresses near fractures in rocks: 671 With applications to faults, joints, veins, dikes, and solution surfaces, in: Atkinson, B.K. (Ed.), 672 Fracture Mechanics of Rock. Academic Press Inc., London, pp. 277-349.

673 Pratt, H.R., Swolfs, H.S., Brace, W.F., Black, A.D., Handin, J.W., 1977. Elastic and transport 674 properties of an in situ jointed granite. International Journal of Rock Mechanics and Mining 675 Sciences \& Geomechanics Abstracts 14, 35-45. 
676 Ritz, E., Mutlu, O., Pollard, D.D., 2012. Integrating complementarity into the 2D displacement 677 discontinuity boundary element method to model faults and fractures with frictional contact 678 properties. Computers \& Geosciences 45, 304-312.

679 Ritz, E., Pollard, D.D., 2012. Stick, slip, and opening of wavy frictional faults: A numerical 680 approach in two dimensions. J. Geophys. Res. 117, B03405.

681 Ryan, K.J., Oglesby, D.D., 2014. Dynamically modeling fault step overs using various friction 682 laws. Journal of Geophysical Research: Solid Earth 119, 5814-5829.

683 Segall, P., McKee, E.H., Martel, S.J., Turrin, B.D., 1990. Late Cretaceous age of fractures in the 684 Sierra Nevada batholith, California. Geology 18, 1248-1251.

685 Segall, P., Pollard, D.D., 1983a. Joint formation in granitic rock of the Sierra Nevada. Geological 686 Society of America Bulletin 94, 563-575.

687 Segall, P., Pollard, D.D., 1983b. Nucleation and growth of strike slip faults in granite. Journal of 688 Geophysical Research 88, 555-568.

689 Segall, P., Simpson, C., 1986. Nucleation of ductile shear zones on dilatant fractures. Geology $69014,56-59$.

691 Sheldon, H.A., Micklethwaite, S., 2007. Damage and permeability around faults: Implications 692 for mineralization. Geology 35, 903-906.

693 Sibson, R., Moore, J., Rankin, A.H., 1975. Seismic pumping - a hydrothermal fluid transport 694 mechanism. Journal of the Geological Society 131, 653-659.

695 Sibson, R.H., 1985. Stopping of earthquake ruptures at dilational fault jogs. Nature 316, 248696251.

697 Sibson, R.H., 1994. Crustal stress, faulting and fluid flow. Geological Society, London, Special 698 Publications 78, 69-84.

699 Stern, T.W., Bateman, P.C., Morgan, B.A., Newell, M.F., Peck, D.L., 1981. Isotopic U-Pb ages 700 of zircon from granitoids of the central Sierra Nevada, California. United States Geological 701 Survey Professional Paper 1185, 17. 
Utada, M., 2001. Zeolites in Hydrothermally Altered Rocks. Reviews in Mineralogy and Geochemistry 45, 305-322.

\section{Figure Captions}

Figure 1. Bear Creek study area in the central Sierra Nevada, California. Left is a topographic map, from the National Atlas of the United States (http://nationalatlas.gov). Right is a geologic map, based on work by Lockwood and Lydon (1975), with photomosaic localities of Figure 2 identified.

Figure 2. Mapped photomosaics from the Bear Creek valley (see Figure 1 for locations). Dashed photomosaic boundary shows extent of photographs, first orthorectified and then stitched together. LHF is the Lower Hilgard Meadows Fault from Griffith et al. (2009). Figure 8 shows photomicrographs from fault $\mathrm{B}$ at the marked core locations.

Figure 3. Definition of a) releasing and restraining bends along a simplified fault shape, with lenticular sections of opening along the releasing bend, and b) rhombochasm formation through four time steps between either two initially distinct faults (left) or two sections of slip along an earlier filled fault (right).

Figure 4. Two sections of fault from the study area with lenticular openings on releasing bends and alteration haloes surrounding the sections of opening. Each fault is shown with a photograph, map, and aperture distribution, where the aperture is measured perpendicular to the general fault trend along the $x$-axis. In the maps, fault surfaces and infill are shown in black, and alteration haloes are gray. Each aperture distribution comprises over 500 measurements, with errors of $\pm 0.1 \mathrm{~mm}$.

Figure 5. a) Two rhombochasms mapped along a fault: b) photograph of rhombochasm between two fault segments, c) photograph of rhombochasms within fault infill. 1-4 show photomicrographs of thin sections taken from core samples in plane polarized light. Transect 1-3 shows alteration (cloudiness) decreasing away from fault, while 4 shows more alteration on the southern side of the fault than the northern.

Figure 6. Extensional steps along several fault segments: photomosaic (top) and map (bottom). Secondary cracks concentrate hydrothermal fluid alteration in the steps, which alters the host rock (gray) and mineralizes the openings (black).

Figure 7. Total apparent aperture, measured in the $y$-direction, along the eastern fault in profile B, Figure 2. Apertures have measurement errors of $\pm 0.5 \mathrm{~mm}$.

Figure 8. Thin section photomicrographs in plane light from three areas along the eastern fault in profile B, Figure 2. Releasing bends (a) and (c) have quartz infill (translucent) with epidote rims (dark green) and cut through highly altered host rock (cloudy feldspar and light green chlorite). Restraining bend (b) has mylonitized quartz infill and host rock, but little to no epidote or alteration. Photomicrographs are rotated so that the fault surface is approximately horizontal. 
Figure 9. a) Slip and b) opening distributions for model faults of varying shape. The adjusted $y^{\prime}-$ coordinates for the planar fault are $y^{\prime}=y \times 0=0$, while the other shapes are half and twice that measured along fault B. Fault shapes shown for reference between the plots. c) Enlargement of section of opening distribution in (b). In these numerical experiments, $\mu=S_{f}=P=0$.

Figure 10. The influence of the coefficient of friction ( $a$ and $b$ ), frictional strength (c and d), and fluid pressure (e and f) on slip (top graphs) and opening (lower graphs) distributions. Each distribution is normalized by the maximum slip for the planar case with $\mu=S_{f}=P=0$.

Figure 11. a) Slip change, equation (2), and b) opening change, equation (3), for a range of 747 frictional properties and fluid pressures.

Figure 12. Resolved normal (gray) and shear (black) remote stresses for each element along the model fault (solid lines) before deformation. Uniform stresses along planar faults with an identical remote stress loading are provided as dashed lines for reference.

Figure 13. Relationships between the coefficient of friction and the frictional, strength normalized by normal stress, where each line indicates the parameter space for which these two terms have equal influence on the magnitude of shear stress.

Figure A1. Schematic problem setup for displacement discontinuity boundary element model. a) Two-dimensional linearly elastic material contains a crack which deforms due to a remote stress loading (positive stresses shown). b) Crack is discretized into $N$ linear boundary elements, each with a local orientation given by normal and shear unit vectors $(n, s)$. C) Each element has a resultant uniform normal and shear displacement discontinuity and representative normal and shear stress at the center.

Figure A2. Percentage change in the greatest magnitude normal and shear displacement discontinuity along the fault, each normalized by the total fault length $L$, which is the sum of all $N$ element lengths. With a sufficient number of elements, the solution changes insignificantly.

767 Figure A4: Decomposed shear displacement discontinuity along an element: see equation (9). 
$125^{\circ} \mathrm{W}$

$40^{\circ} \mathrm{N}$

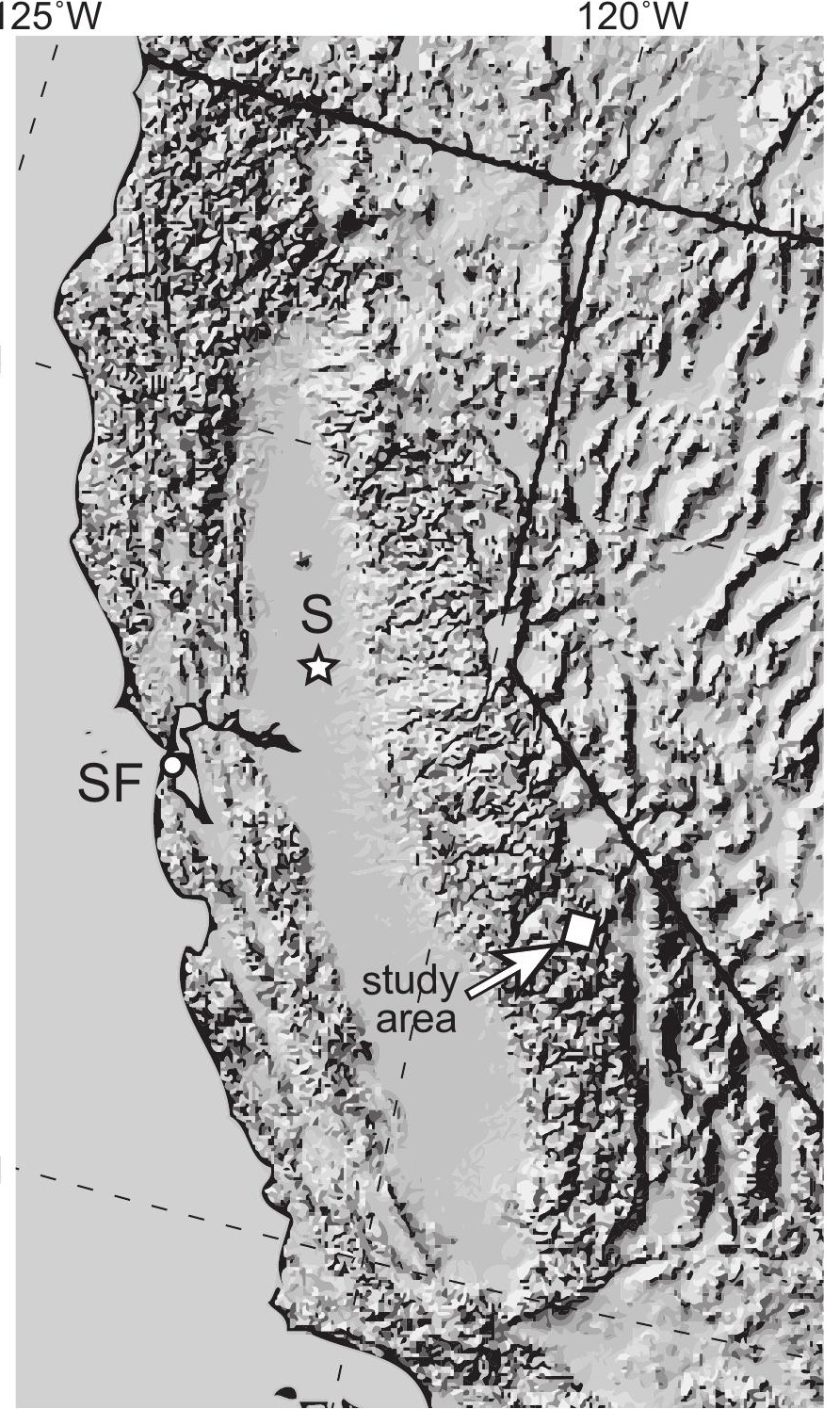

$118^{\circ} 53^{\prime}$

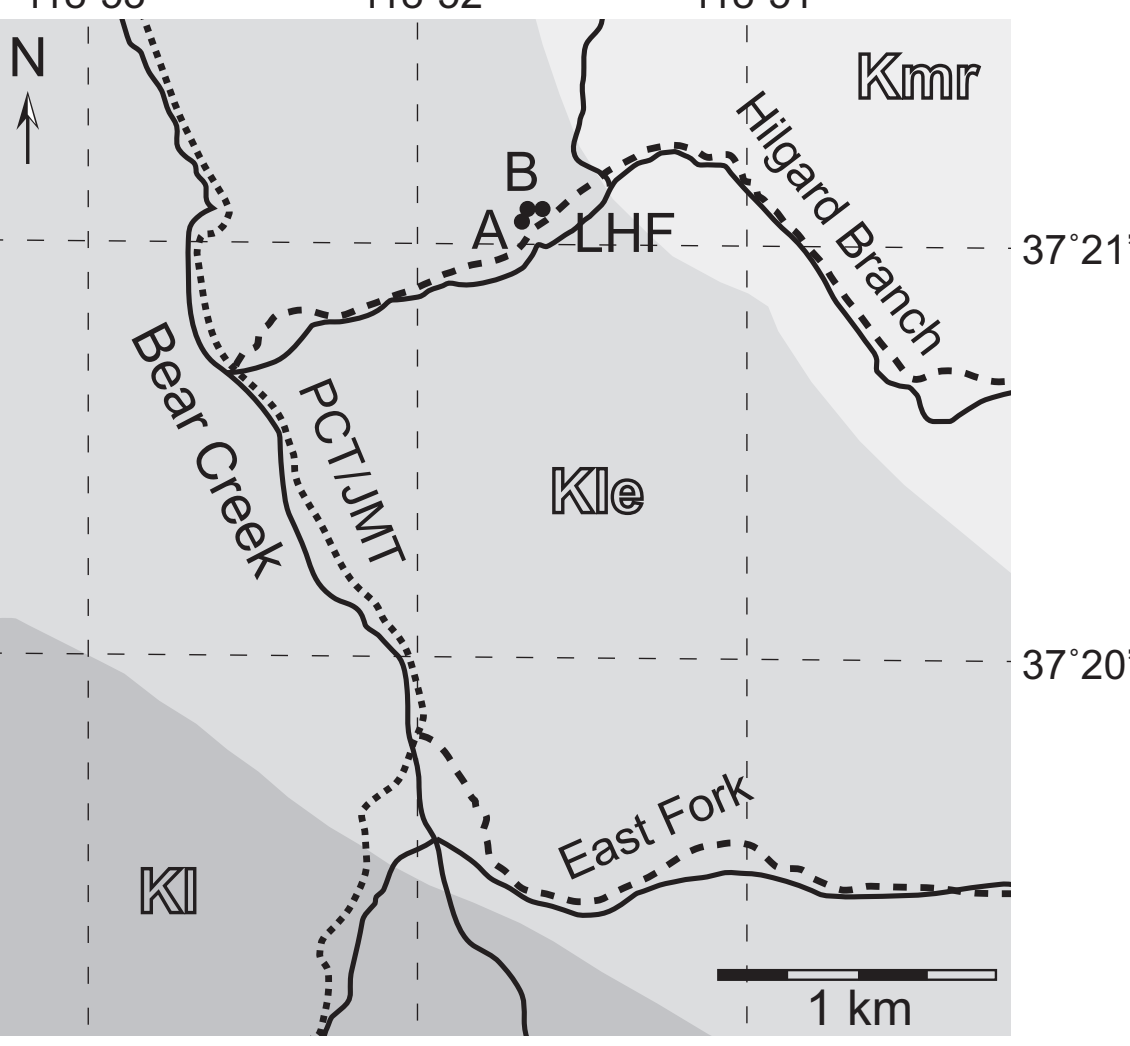

$\square$ Mono Recesses Quartz Monzonite, Kmr

$\square$ Lake Edison Granodiorite, Kle

$\square$ Lamarck Granodiorite, KI

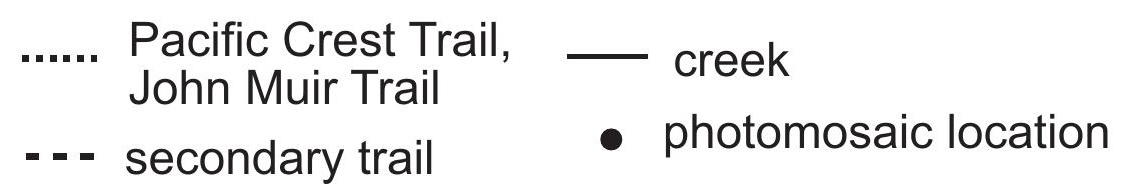




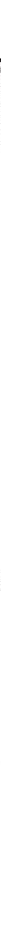


a) lenticular opening: $\leftrightharpoons{ }^{r_{\text {straining }}} \underbrace{r_{\text {estraining }}}$

b) rhombochasm formation:
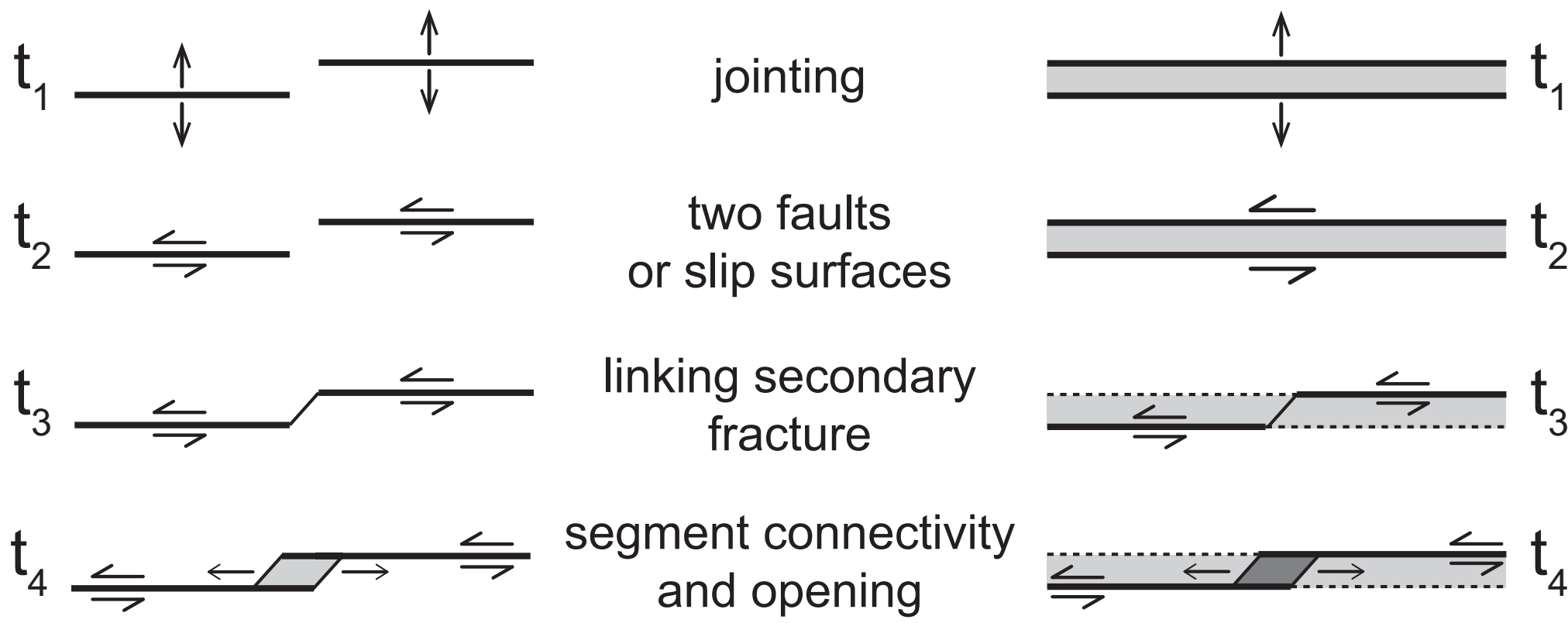
- active fault segment or surface
.... inactive fault segment or surface
secondary fracture
earlier infill 
a) $\quad y_{\uparrow}$
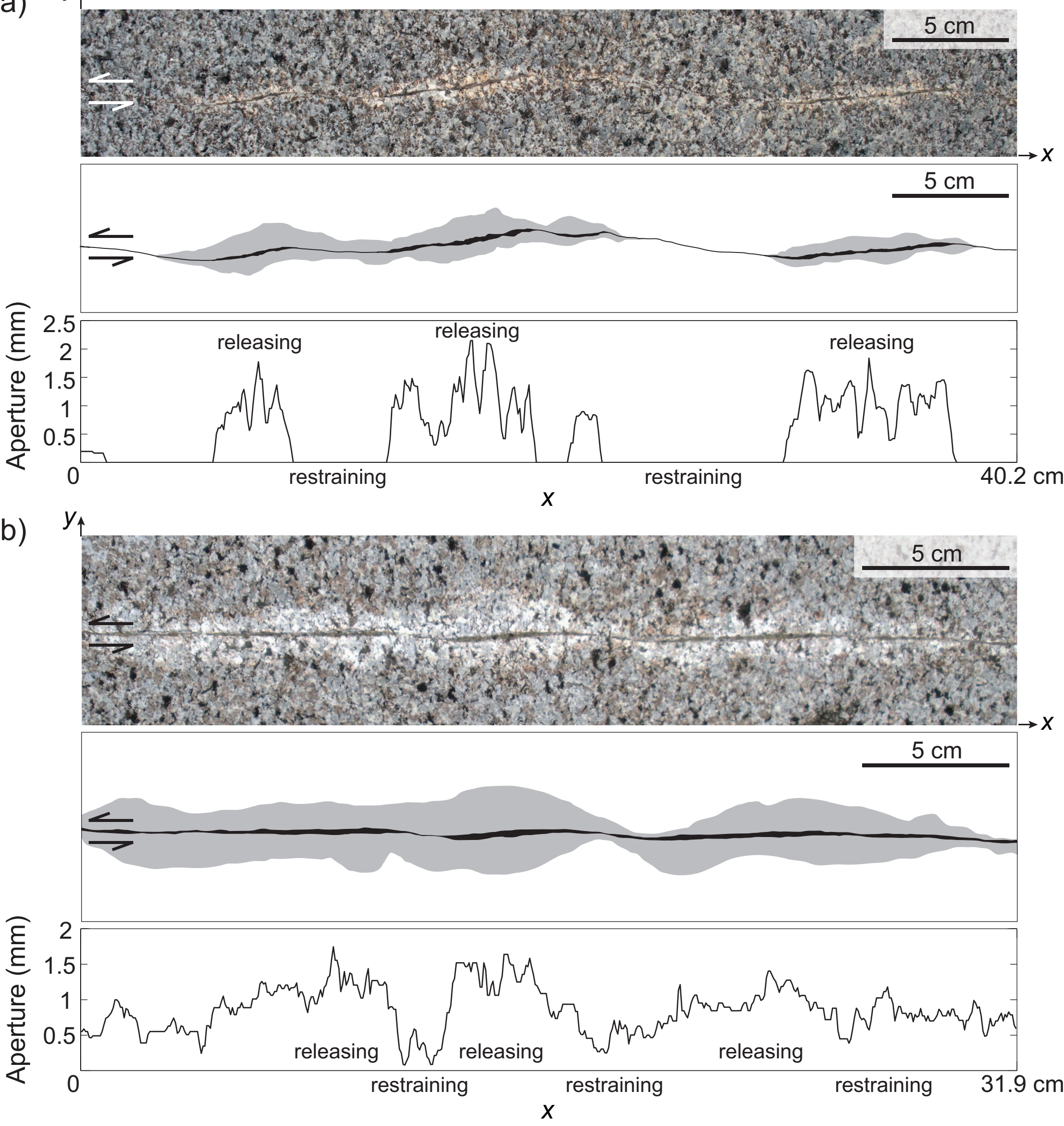

8

b) 


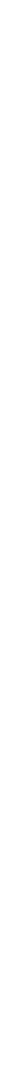



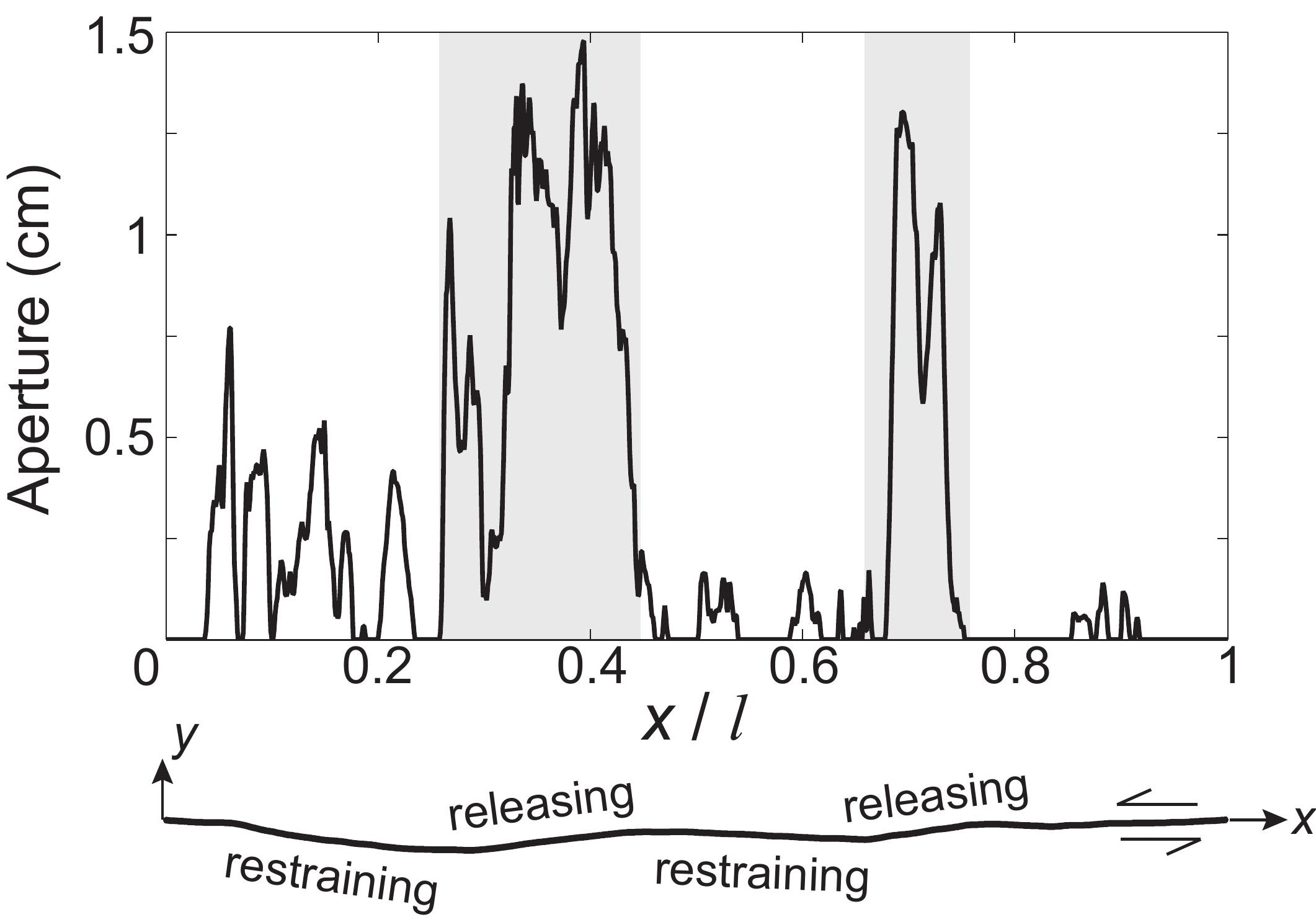

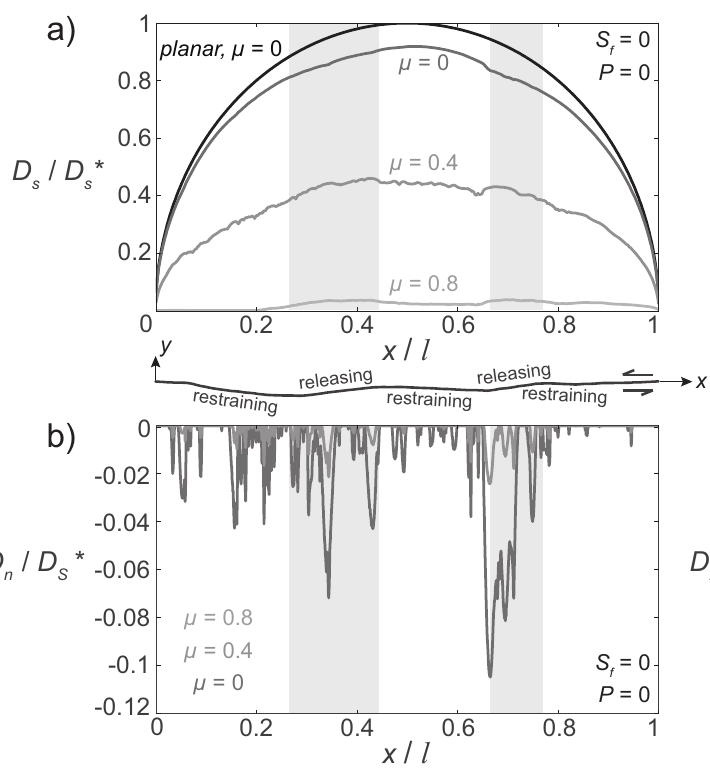

c)

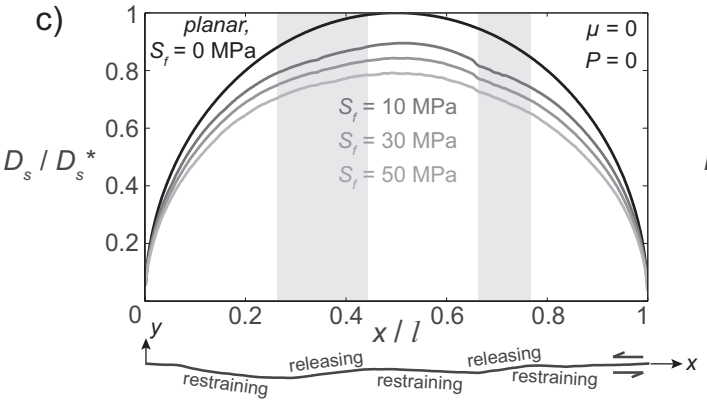

d)

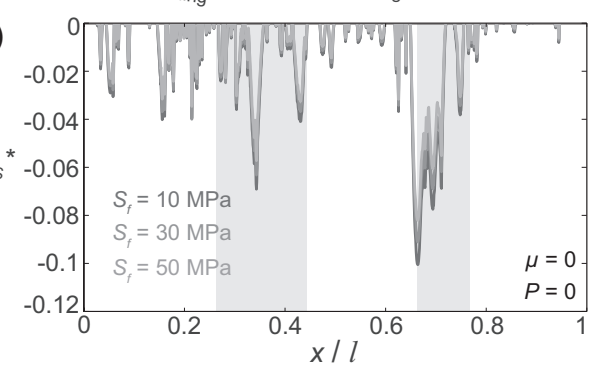

e)

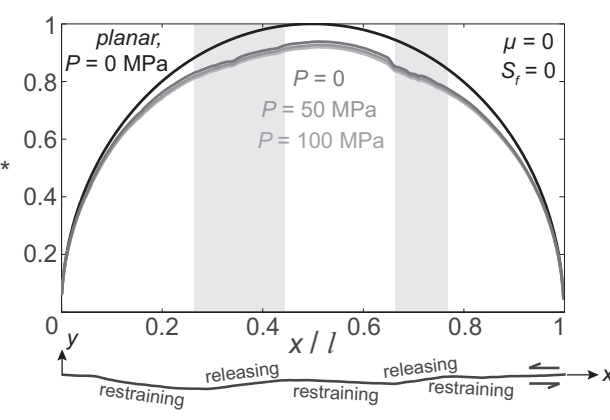

f)

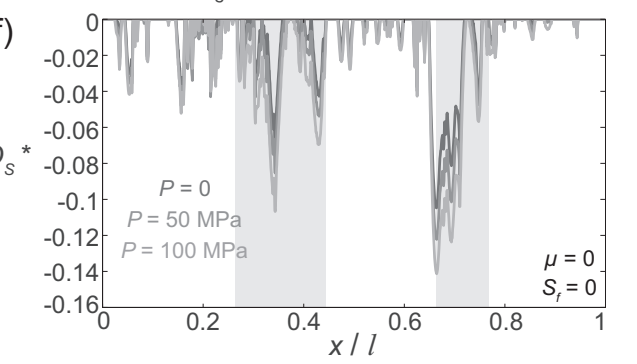


a)

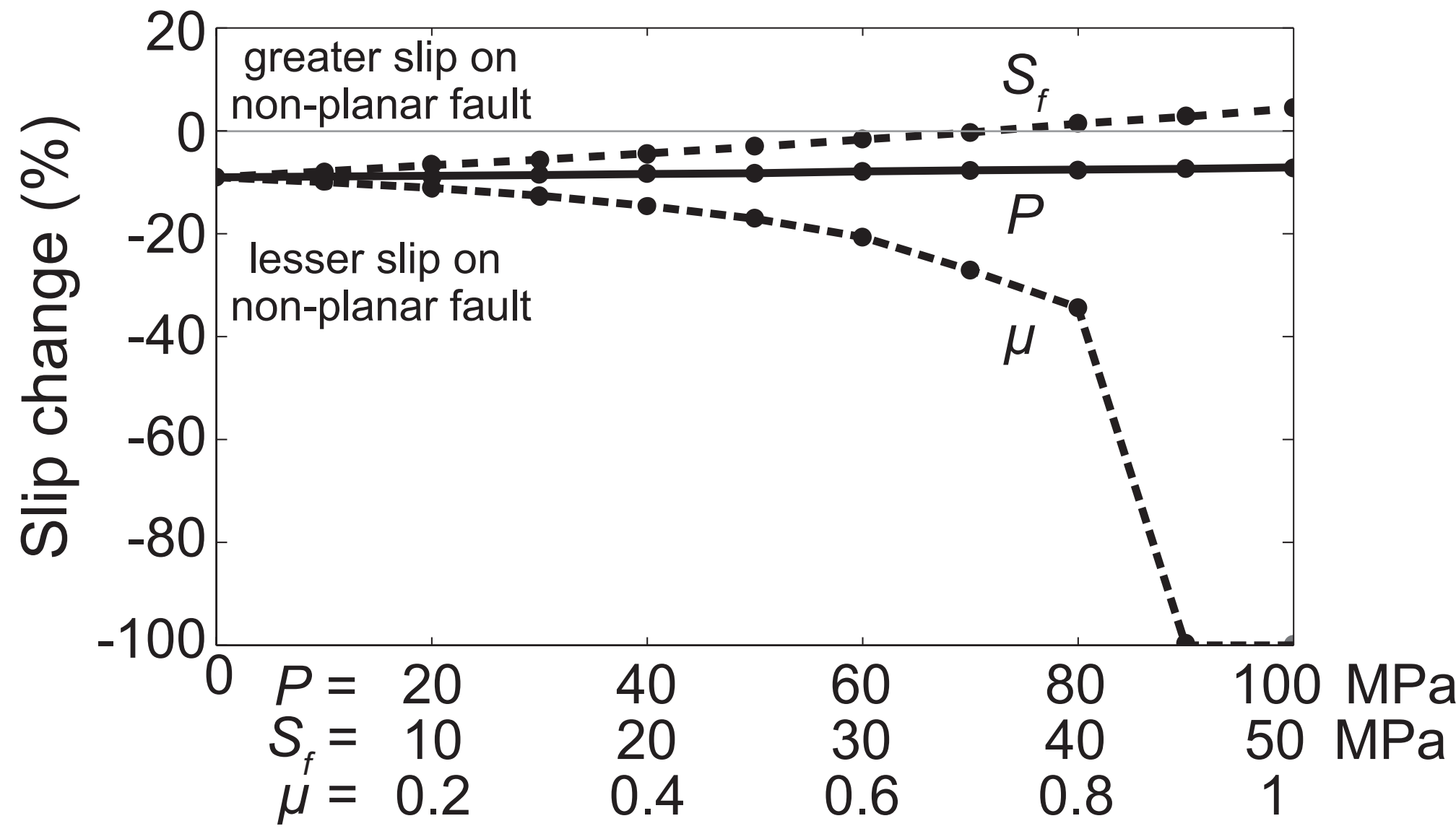

b)

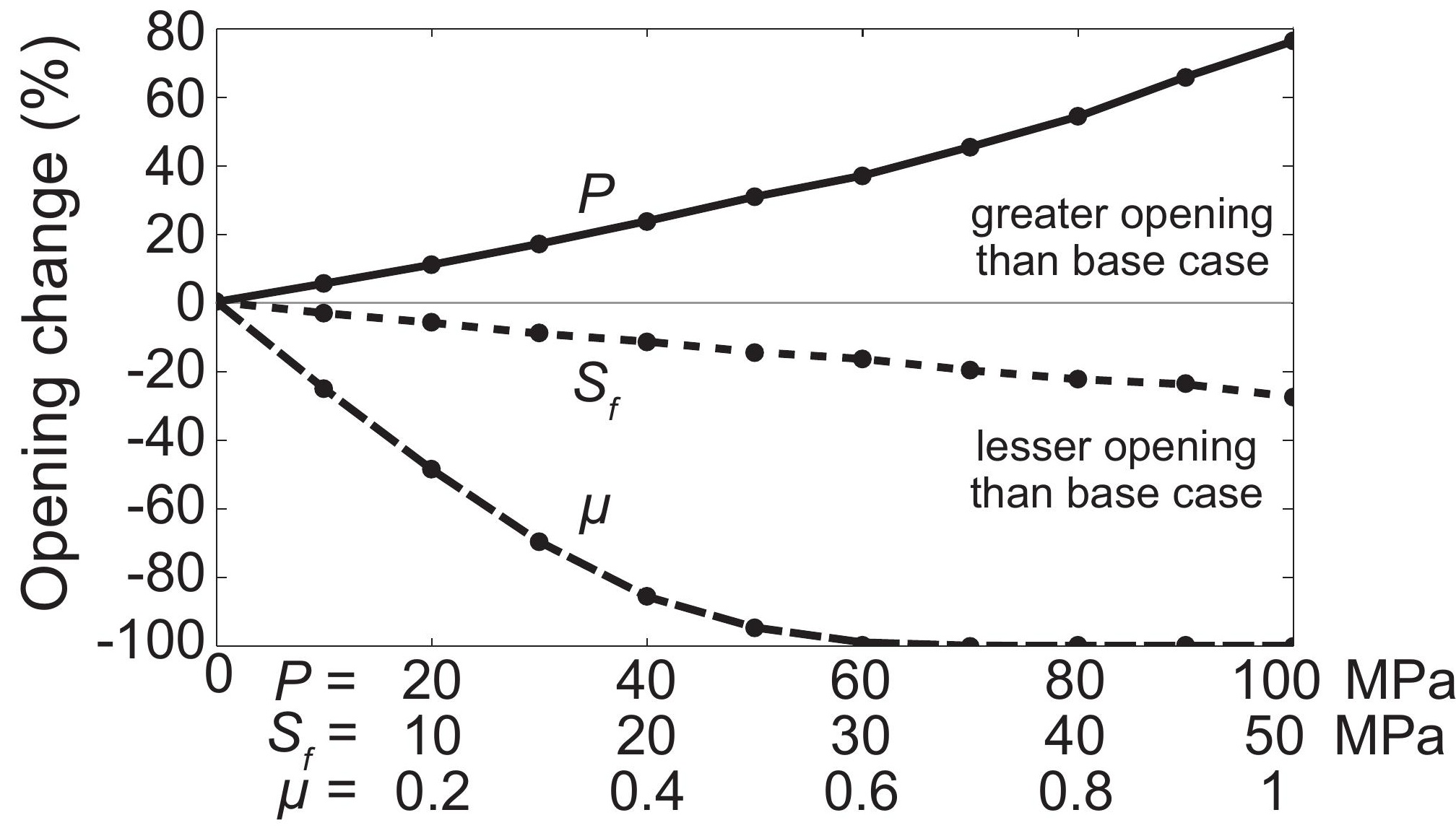




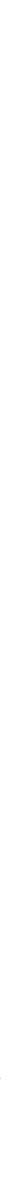




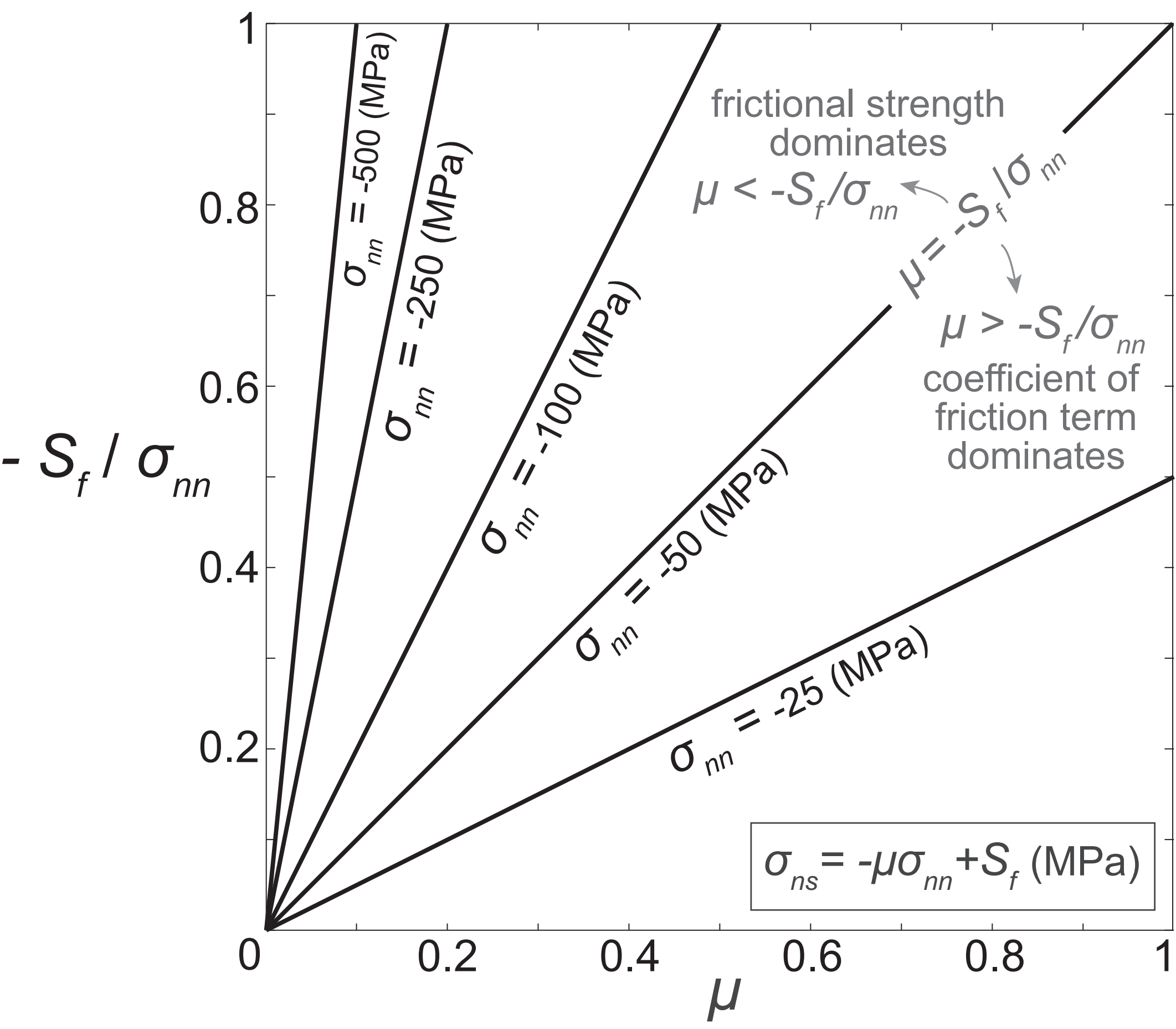




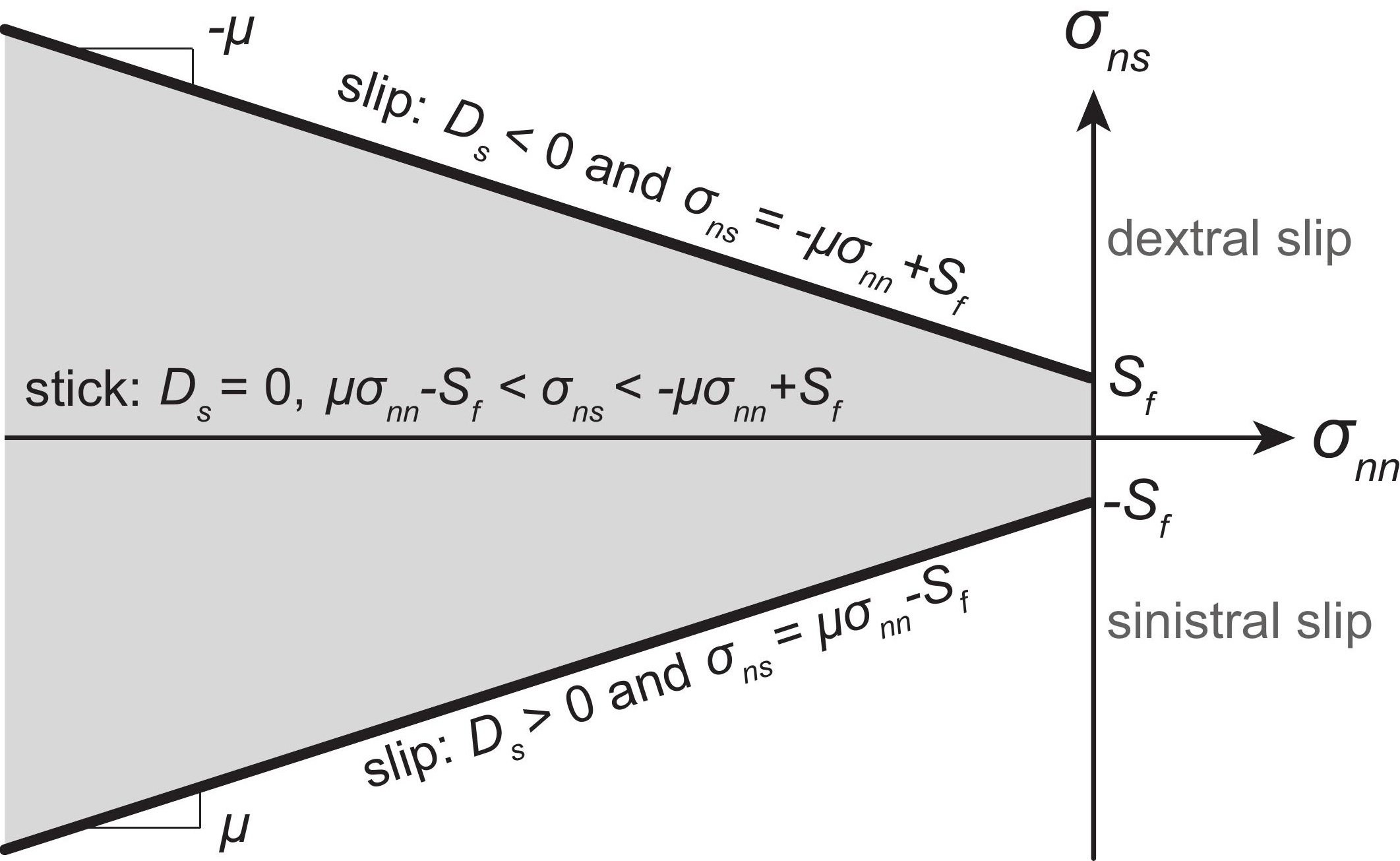

stick: $D_{s}=0, \mu \sigma_{n n}-S_{f}<\sigma_{n s}<-\mu \sigma_{n n}+S_{f}$ 
a) dextral slip, $D_{s}^{L}=0$

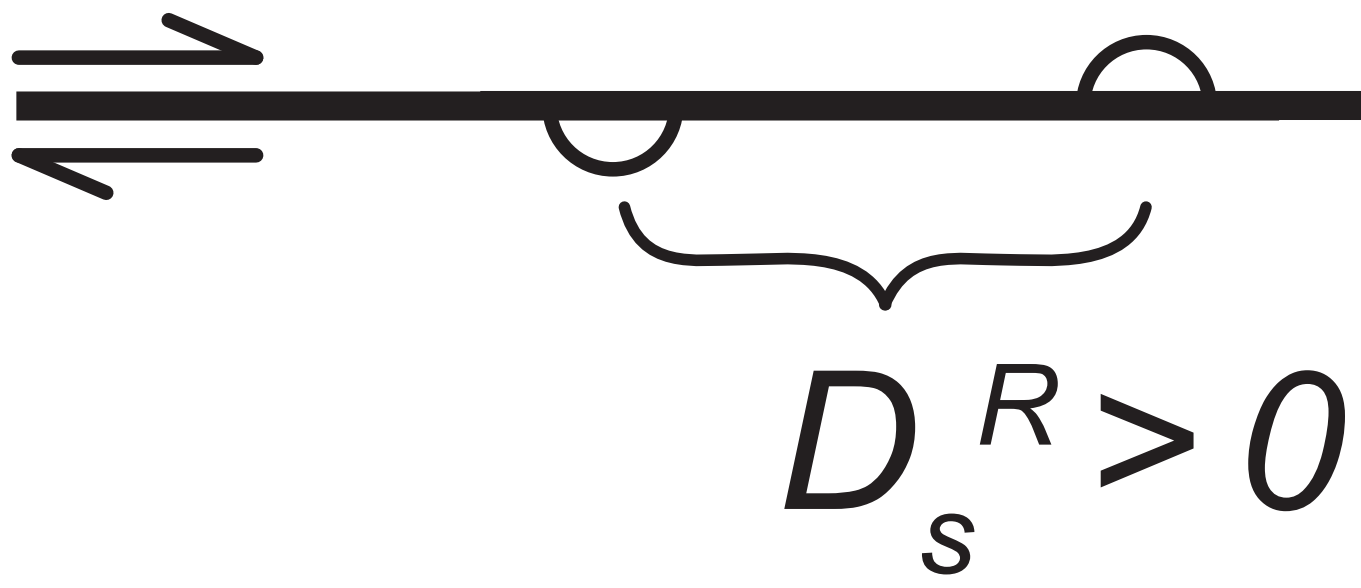

b) sinistral slip, $D_{s}^{R}=0$

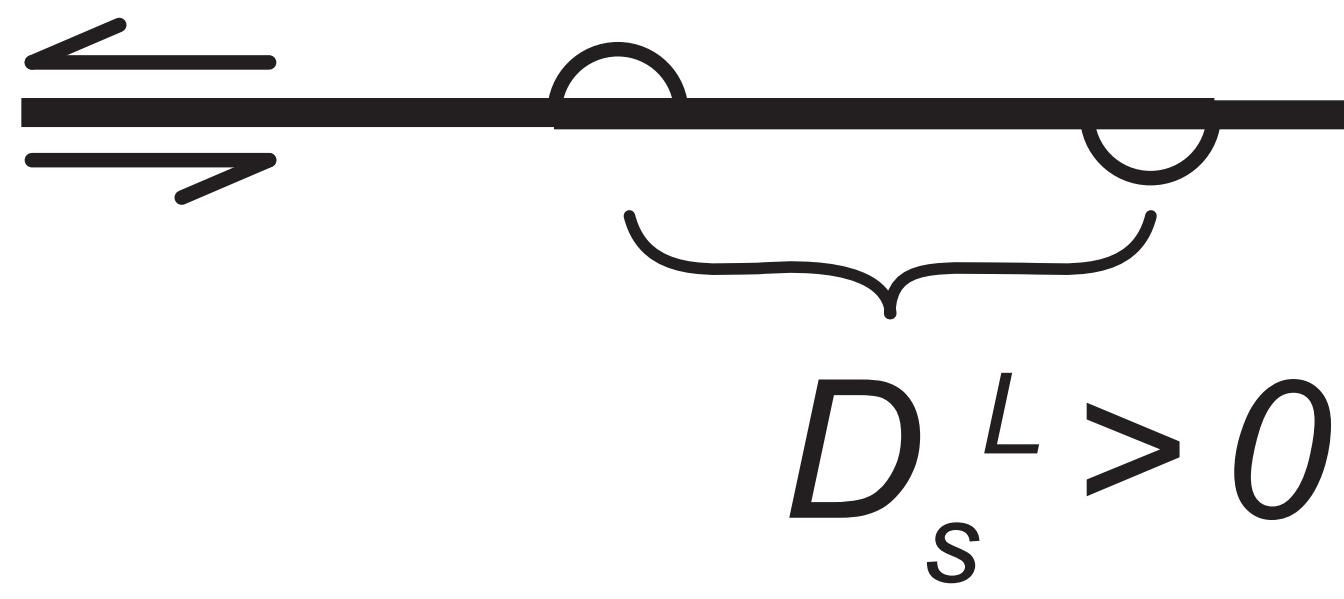
C)
stick,
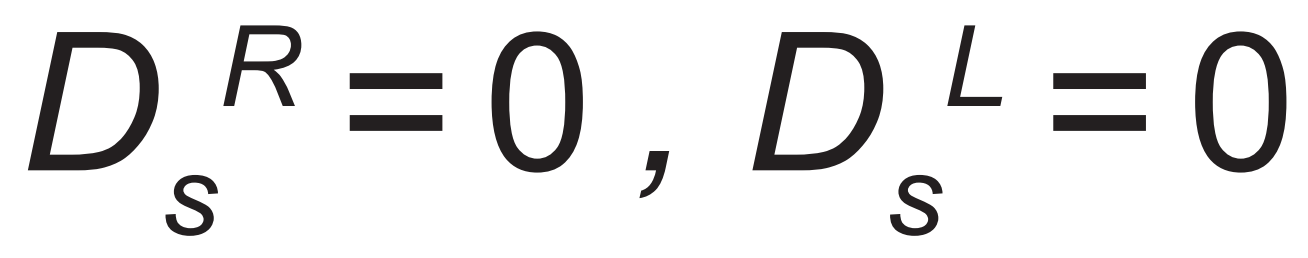

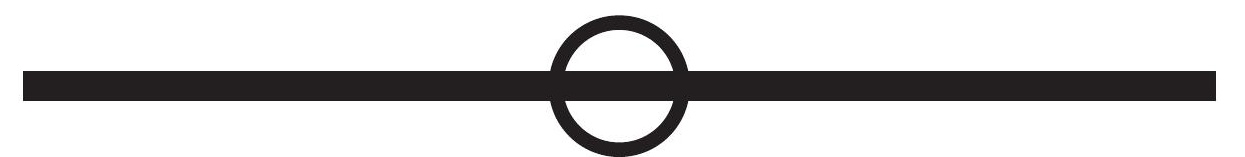

